\title{
WestVirginiaUniversity
}

THE RESEARCH REPOSITORY @ WVU

Graduate Theses, Dissertations, and Problem Reports

2006

\section{Perspectives of key stakeholders with regard to extended school year programs}

Billie E. Bonnett

West Virginia University

Follow this and additional works at: https://researchrepository.wvu.edu/etd

\section{Recommended Citation}

Bonnett, Billie E., "Perspectives of key stakeholders with regard to extended school year programs" (2006). Graduate Theses, Dissertations, and Problem Reports. 4215.

https://researchrepository.wvu.edu/etd/4215

This Dissertation is protected by copyright and/or related rights. It has been brought to you by the The Research Repository @ WVU with permission from the rights-holder(s). You are free to use this Dissertation in any way that is permitted by the copyright and related rights legislation that applies to your use. For other uses you must obtain permission from the rights-holder(s) directly, unless additional rights are indicated by a Creative Commons license in the record and/ or on the work itself. This Dissertation has been accepted for inclusion in WVU Graduate Theses, Dissertations, and Problem Reports collection by an authorized administrator of The Research Repository @ WVU.

For more information, please contact researchrepository@mail.wvu.edu. 


\title{
Perspectives of Key Stakeholders \\ with Regard to Extended School Year Programs
}

\author{
Billie E. Bonnett \\ Dissertation submitted to the \\ College of Human Resources and Education \\ at West Virginia University \\ in partial fulfillment of the requirements \\ for the Degree of
}
Doctor of Education
in
Special Education

\author{
Dr. Ann Richards, Chair \\ Dr. Gretchen Butera \\ Dr. Helen Hazi \\ Dr. Ruthellen Phillips \\ Dr. Richard Walls \\ Dr. Diane Woodrum \\ Department of Education Theory and Practice \\ Morgantown, West Virginia \\ 2006
}

Keywords: Extended School Year, Regression, Recoupment

Copyright 2006 Billie E. Bonnett 


\author{
Abstract \\ Perspectives of Key Stakeholders \\ with Regard to Extended School Year Programs
}

Billie E. Bonnett

There is growing concern about the impact of summer vacation on the academic achievement of our children, especially those with special needs. In recognition of the magnitude of this problem, the Individuals with Disabilities Education Act (IDEA), 1999, described the need for extended school year services. Additionally, IDEA, 2004, sought to clarify and further define extended school year services. This addition to IDEA provides guidance, but it does not change the previous provisions. Research suggests that effective extended school year programs include essential components: child centeredness, family involvement, community involvement and school commitment. Despite these regulations, key stakeholders including teachers, administrators, service providers, and parents do not have a clear understanding of extended school year programs and are unaware of the total range of services available. The barriers to providing appropriate extended school year services for children with special needs appear to be insurmountable, and as a result, these children continue to regress academically, behaviorally, and socially. The purpose of this study was to examine the relationship between what key stakeholders believe about extended school year, the practices implemented, and how they are meeting the needs of students with special needs in extended school year programming. A case study design was used to provide thick, rich, descriptions of how two school districts deliver extended school year services in West Virginia. Observation and interview data were. Theme and cross-case analysis was completed. This pattern matching examination indicated that the beliefs of both school districts are virtually the same; however, the delivery of services is vastly different. Implications and limitations are also discussed. 


\section{Acknowledgements}

I would like to take this opportunity to expression a sincere thank-you to the members of my committee, Dr. Helen Hazi, Dr. Ruthellen Phillips, Dr. Richard Walls, and Dr. Diane Woodrum for their support, guidance, and patience. I am forever grateful to Dr. Ann Richards, who graciously agreed to chair my committee at "the eleventh hour”.

Words cannot express the depth of my appreciation for Dr. Gretchen Butera. Without her encouragement this dissertation would never have been written. In addition to being my mentor, she became my friend. Her insight, guidance, and belief in me kept me focused and determined to finish. Thanks, Gretchen!

I am most thankful for my family, especially my husband Ronnie, who always understood the importance my work and never complained about the time I needed to spend in class, at the library, on the computer, and out of town. My grandchildren will never again hear the words, "Nana can’t play today. She has to work on her paper."

Last, but certainly not least, I would like to thank my sister, Kathy. If I could share my degree with another person it would be her. She has been my typist, my cheerleader, my dictator, my inspiration, and my friend. She deserves this doctorate degree as much as I do!

My only regret is that my mother did not live long enough to see the completion of my degree. I know she would be proud! 
Table of Contents

Acknowledgements iii

List of Tables vi vi vis

Chapter I: Introduction 1

Needs of Children in the Summer 3

Efficacy of Extended School Year Programs 4

$\begin{array}{ll}\text { Successful Summer Programs } & 6\end{array}$

$\begin{array}{ll}\text { Problem Statement } & 8\end{array}$

$\begin{array}{lr}\text { Purpose of Study } & 9\end{array}$

$\begin{array}{lr}\text { Research Questions } & 9\end{array}$

$\begin{array}{ll}\text { Operational Definitions } & 10\end{array}$

Chapter II: Literature Review 12

Extended School Year Program Definition $\quad 12$

Legislative History of Extended School Year Programs 13

Judicial History of Extended School Year Programs 16

$\begin{array}{ll}\text { Eligibility Criteria for Extended School Year Programs } & 18\end{array}$

Essential Components for Successful Extended School Year Programs 23

Policy 31

$\begin{array}{ll}\text { Structures } & 34\end{array}$

Challenges $\quad 35$

Chapter III: Method 42

Introduction $\quad 42$

Purpose of Study $\quad 42$

Research Questions $\quad 42$

Case Study Research $\quad 43$

$\begin{array}{ll}\text { Selection } & 45\end{array}$

$\begin{array}{ll}\text { Instrumentation } & 50\end{array}$

$\begin{array}{ll}\text { Observation } & 51\end{array}$ 
Documentation $\quad 52$

Interview $\quad 52$

Home Visitation $\quad 53$

Data/Cross Case Analysis $\quad 55$

Chapter IV: Case Studies $\quad 57$

$\begin{array}{ll}\text { Coal County } & 57\end{array}$

Coal County Talks About Their Extended School Year Program 59

Diary of an Extended School Year Program 69

Putting it All Together $\quad 82$

$\begin{array}{ll}\text { Park County } & 84\end{array}$

Park County Talks About Their Extended School Year Program 86

Extended School Year at a Glance 96

Putting It All Together 118

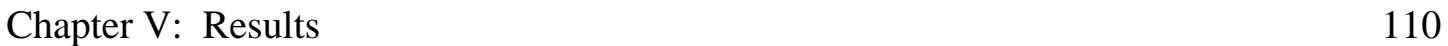

$\begin{array}{ll}\text { Purpose of Study } & 110\end{array}$

$\begin{array}{ll}\text { Research Questions } & 110\end{array}$

$\begin{array}{ll}\text { Cross Case Analysis } & 111\end{array}$

$\begin{array}{ll}\text { Discussion } & 124\end{array}$

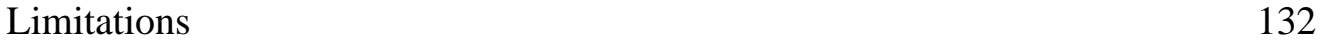

$\begin{array}{ll}\text { Conclusion } & 133\end{array}$

$\begin{array}{ll}\text { References } & 136\end{array}$

Appendices

$\begin{array}{lll}\text { A } & \text { Letter of Request } & 146\end{array}$

B Anecdotal Classroom Observation Protocol 147

$\begin{array}{lll}\text { C } & \text { Cover Script for Interview } & 149\end{array}$

D Administrator Interview Protocol 150

E Service Provider Interview Protocol 152

F Teacher Interview Protocol 154

G Parent Interview Protocol 156

H Extended School Year 2003 Critical Skills Checklist 158

$\begin{array}{lll}\text { I } & \text { Extended School Year Documentation Form }\end{array}$ 
List of Tables

$1 \quad$ Sample of Extended School Year Programs Offered in West Virginia 49

2 Observation/Interview Schedule $\quad 54$

3 Data Collection $\quad 56$ 


\section{Chapter 1}

\section{Introduction}

No more pencils! No more books! No more teachers’ dirty looks! Dennis loves summer, but summer does not love Dennis. His favorite time of year is also the most detrimental to him. During the school year, Dennis struggles to keep up with his classmates. His word recognition and reading comprehension are well below grade level. His math skills are equally deficient. Each summer Dennis, like other children with special needs, falls further and further behind his classmates because of a lack of continuous academic and social stimulus.

There is growing concern about the impact of summer vacation on the academic achievement of our children (Butera, McMullen, and Phillips, 2000; Harvey, 1995; McGill Franzen, 2001; Patten \& Robertson, 2002). With every summer break, many children fail to maintain and some even lose essential academic skills and socially appropriate behaviors. This is especially true of children with disabilities. When there is an absence of summer learning, children with disabilities gain very little academically (Cooper, 2003). Children without disabilities, on the other hand, are able to maintain academic skills, particularly in reading. These differences have been attributed, in part, to what exposure to learning the child experiences outside of the school walls. It is becoming more and more obvious that something has to be done to correct these problems.

Too many young people - of all colors, and all walks of life - are growing up today unable to handle life in hard places, without hope, without adequate attention, and without steady internal compasses...as a result, we are on the verge of losing two generations of children and youth to drugs, violence, too-early parenthood, poor health, 
and education, unemployment, family disintegration and to the spiritual and physical poverty that both breeds and is bred by them (Hixson, Gholar, \& Riggs, 1996, p. 1). Criminal behavior, gang involvement, teen pregnancy, alcohol, and drug abuse are all too familiar issues facing families today, and literature indicates these behaviors manifest more often after school and during the summer months (Cotton, 1997; Hixson et al., 1996; Lockwood, Stinnette, \& D’amico, 1996; Patten \& Robertson, 2002). Many times parents are unable or unwilling to provide structured educational opportunities for their children at home (Bar-Lev, 1998), and parents of students with disabilities are no exception. A lack of resources during the summer months result in scarce programming, especially in rural areas. Isolated, rural areas make it difficult for children to make use of urban-based resources such as museums, libraries, and colleges (Maynard \& Howley, 1997). Children with disabilities in rural areas are profoundly affected by breaks in their academic learning, thus making consistent progress difficult (Butera et al., 2000; Maynard \& Howley, 1997). Essential skills are easily lost during the summer, and it is extremely burdensome and demanding for children with disabilities to regain what was lost (Cooper, 2003; Lockwood et al., 1996; McGill - Frazen, 2001).

In response to these problems, the Individuals with Disabilities Education Act (IDEA), 1999, established federal provisions that describe extended school year services (Stinson, n.d.). These regulations lack clarity, however. Children with disabilities are entitled to free educational services beyond the regular school year when eligibility criteria are met. Nevertheless, after countless court cases, the courts remain reluctant to provide specific guidelines as to eligibility, regression/recoupment criteria and duration of extended school year programs. States and counties interpret the law differently. As a result, extended school year services are offered in a 
variety of ways across the nation (Olmi \& Walker, 1995). In 2004, IDEA was reauthorized. Consequently, the section pertaining to extended school year was changed.

Regulation 300.309 has been revised, and a new paragraph (a) (3) has been added to this section to specify that (1) ESY services must be provided only if a child's IEP team determines the services are necessary for the provision of FAPE to the child; and (2) Public agencies may not limit eligibility for ESY services based on category of disability and may not unilaterally limit types and amounts of ESY services (Council for Exception Children, n.d.).

This added paragraph does provide some guidance but it does not essentially change the previous provisions. While this regulation may impact how school districts interpret the law, it remains to be seen what effect this added paragraph has on extended school year across the nation.

Needs of Children in the Summer

It is of the utmost importance that the needs of children are met, not just during the school year, but during the summer months also. However, while maintaining educational skills is a necessity, summer education must address nutritional needs, health/safety issues and teach students alternatives to at-risk behaviors. In the summer, these needs can be addressed so as not to “look like school” (Butera 2001; Butera et al., 2000; Garland \& Osborne, 2000). Extended school year programming is one possible solution.

Children want to be in safe places where they can be with caring adults and other young people (Patten \& Robertson, 2002). Extended school year programs offer children a safe haven, free from worries and fears. Children who spend time alone, either after school or during the 
summer, are more likely to engage in unacceptable practices and become victims or instigators of crime (Cotton, 1997; Hixson et al., 1996; Patten \& Robertson, 2002). When children with disabilities and other young people are in situations where they are monitored, as they are in summer programs, there is better academic achievement, less depression, less delinquent behavior, and less sexual behavior (Cooper, 2003; Jacobson \& Crockett, 2000).

\section{Efficacy of Extended School Year Programs}

There are many excuses but no real reasons why the needs of America’s children are not being met during the summer months. The existing services are minimal; those which are functioning are inadequate, and there is a dearth of information concerning them. Rural areas are especially vulnerable since communities lack programs to encourage the educational and social development of children (Butera et al., 2000; Harvey, 1995).

Across the nation, the system of record keeping for various services that might address children's needs during the summer months is not universal and tends to be ineffective. The delivery system is very fragmented, and most families do not receive all of the benefits for which they are eligible. For example, in California a disadvantaged family with school-aged children experiencing multiple needs had to appear, complete applications, and tell their story at seventeen different locations in order to access all the services for which they were eligible. In Arkansas, a family of six is served by 25 different human services professionals (Cotton, 1997).

Further, social service agencies are often crisis-oriented. In other words, there has to be a major problem for agencies to become involved. The research also indicates agencies are not aware of each other and the services that can be offered. In addition, agencies do not access informal systems. Social service agencies generally do not acknowledge and utilize informal 
community helping systems, such as community centers and churches, which could help them reach clients and extend services (Anderson, 2000; Cotton, 1997). Furthermore, there are legal problems which prevent churches and ethnic clubs from obtaining funding.

School systems are uninformed as to the type of summer programs that might be appropriate for students with disabilities. While summer school is more familiar to the education community, extended school year programming for students with disabilities is still a mystery. Traditionally, summer school is provided for those students who have failed or are behind in their course work. On the other hand, extended school year offers a continuum of programming for students with disabilities who meet eligibility criteria. A lack of communication between school administration and local community agencies contributes greatly to the inefficiency of services delivered to children with disabilities. This situation is especially true in the case of programs that are not offered during regular school time (Bonnett, 2002b).

Overall, the research indicates teachers are unaware of the total range of services which are available for children in their communities. Schools tend to match students and services in a very informal way (Anderson, 2000; Cotton, 1997; Honig, Kahne \& McLaughlin, 2001). As a result, many children with disabilities are eligible for extended school year services they are not currently receiving. At times, the barriers between available services and delivered services for children with disabilities appear to be insurmountable.

For children with disabilities, extended school year programs have the potential to meet student needs during the summer. Extended school year does not have to differ from a child's education during the year, but must meet the requirements of the IEP. Because extended school year services are not always provided by the same teachers the students have during the school 
year, it is imperative that the program be consistent with the goals and objectives as determined by the IEP. However, it is also the case that extended school year can be designed to enrich a child's regular education. At issue is whether the school can provide professional personnel to deliver an appropriate extended school year program. Additionally, once a qualified person has been selected as a service provider for extended school year services, how is pertinent information on each child obtained? Is there communication established between the child's classroom teachers and the service provider? Is the service provider given access to the child's IEP?

Several studies have been conducted to determine the effectiveness of extended school year programming for children with special needs. Language skills acquisition was the most prominent area addressed. Acceleration and language-skills acquisition for hearing impaired children and significant gains in cognitive and language processes have been reported. However, it is interesting to note that most studies have not provided base-line data on pupil performance at the end of the school year (McGill - Franzen, 2001). Given the variability of extended school year programs, it is not clear whether they do in effect provide educational benefit. It becomes essential, therefore, that extended school year programs have clear, concise goals.

\section{Successful Summer School Programs}

Research indicates that successful summer learning experiences increase self-esteem and self- confidence. Positive peer relationships enhance motivation and contribute to better attitudes about learning. At the same time, values must be taught in order to broaden the social skills needed to be successful. Opportunities must be provided for children to become selfconfident, contributing members of society (Anderson, 2000; Bonnett, 2002a; Butera, 2001; 
Butera et al., 2000).

Programs must be reorganized to include ways to better meet the basic needs of children (Cotton, 1997; Harvey, 1995; Honig et al., 1999; Stagner \& Duran, 1997). Safe and healthy environments (including nutritional concerns) that support learning must be provided to meet the needs of families so those with the greatest needs are not left behind. Children and their families need to connect with neighborhoods, communities, and places where they can feel at home (Anderson, 2000; Perras, 2002).

The major goal of the school system for the summer should include effective follow through. Schools should have a continuum of services beginning with early learning throughout school years. Extended school year programming provides this continuum of services for children with disabilities. As a result, there must be a follow-up of performance levels in order to make services such as extended school year more effective (Cooper, 2003; Harrington, 1994; Harvey, 1995).

Improvements must be made in school climate. Schools must be places where children feel safe and nurtured. Summer programs may be a time when schools can improve their community relationships. This could be a time for school-community connections to be strengthened. Opening the schools for various community events is one way to foster good public relations. In addition, holding an “open house” for members of the community to observe the daily operations of summer programming would help to bridge the gap between school and community.

Schools may also focus on parent involvement during the summer. Parents of children with disabilities should be encouraged to visit extended school year programs and become 
actively involved. This could be accomplished through communication with service providers. Schools should take the initiative in encouraging parents to volunteer in classrooms (Maynard \& Howley, 1997).

Community agencies play an invaluable part in the lives of children especially in the summer. Meeting the non-academic needs of students helps reduce absenteeism and improves grade point averages. Students come to school better prepared and in a better frame of mind. Services offered through agencies should be easily accessible. Children are more likely to use them if they are located at or near a public school. Information about services should be distributed throughout the community on a regular basis. These issues can be addressed during summer programs (Harvey, 1995; McGill \& Franzen, 2001; Honig, Kahne, \& McLaughlin, 1999; Patten \& Robertson, 2002).

\section{Problem Statement}

Regression is experienced by millions of school children each summer within the state and the nation. Regression is defined as a loss of academic skills in the absence of continuous instruction caused by school breaks and summer vacations. Additionally, socialization skills are affected by the lack of significant interaction with peers.

Research has provided some important descriptions of effective summer programming, and federal regulations provide some guidance. Yet, school districts across the country continue to struggle to provide effective extended school year programs for students with disabilities. Why is an effective response not forthcoming? Key stakeholders are often unaware of the problems associated with extended school year programming and are uncertain as to the framework of an effective extended school year program (Bonnett, 2002). 
Purpose of the Study

The purpose of this study is to examine the relationship between what people believe about extended school year services, their knowledge of extended school year services and effective extended school year programming. This study will specifically focus on the perspectives of key stakeholders: parents, teachers, administrators, and service providers. Emphasis will be placed on determining how extended school year programming meets the needs of children with disabilities. The following research questions will frame the research:

1. What are the beliefs of key stakeholders (parents, teachers, administrators, and service providers) about extended school year? How do these perceptions compare/contrast with one another?

2. How do the practices of extended school year programs relate to the essential components of a successful summer program for children with special needs?

3. What is the relationship between the beliefs of key stakeholders and the practices implemented during extended school year programming? 


\section{Operational Definitions}

After School Programs: Programs designed to provide care for, and educational enhancement to children in the hours immediately following school classes.

Anecdotal Journal: Data obtained by direct observation and recorded in narrative form..

Essential Skills: Activities that assist a child in becoming independent in his or her environment.

Extended School Year: Educational programming beyond the traditional 180 day school year for eligible students with disabilities as outlined by the Individuals with Disabilities Education Act (IDEA).

Field Journal: A continuous record of decisions made during data collection as a result of documentation and reflection of the ongoing research process.

Field Notes: Data recorded while on-site observations are being conducted. Individualized Educational Plan (IEP): A written education plan, mandated by law, for a school-aged child with disabilities developed by a team of professionals, and the child's parents that define a child's disability, states current levels of educational performance, describes the child's learning and educational needs, what service the child will need, and specifies annual goals and short-term objectives.

Key Stakeholders: Individuals who have special knowledge, status, or interest in a given topic. Low Inference Descriptors: Verbatim accounts of conversations, and precise descriptions of actions by participants.

Member Checking: A means to check, with participants, for accuracy and confirmation of research findings.

Multiple Data Collection: A means of gathering information using a variety of strategies 
including surveys, observations, interviews, and home visitation.

Perceptions: The ideas of an individual based on experience, beliefs, and values.

Pilot Study: Initial research conducted to determine issues related to a particular topic.

Recoupment: To recover the equivalent of what has been lost. In the case of a student, the amount of time to regain skills previously acquired.

Regression: The loss of academic skills in the absence of continuous instruction caused by school breaks and summer vacations.

Summer Programming: Activities designed to address student needs during the summer months when school is not in session. 
Chapter 2

Literature Review

School systems today are part of a rapidly changing world. In the past, schools have been dependent solely upon resources within the educational system. As society has changed, the importance of schools working within the realm of the community has become evident. The widespread isolation of individual families has resulted in the deterioration of neighborhoods. Consequently, local government agencies have teamed with schools in order to strengthen their services for the family.

The purpose of this review is to examine the literature that has been published regarding summer programs for youth and discuss the issues surrounding extended school year programming, in particular. A definition of extended school year programming will be reviewed. Issues addressed will include the legislative and judicial history of extended school year programs including policy and structure. Eligibility for extended school year programs and the criteria used will be discussed. Research regarding the effectiveness of extended school year programs will be reviewed and finally, essential components of services, as well as the challenges involved in providing extended school year programming will be addressed.

\section{Extended School Year Program Definition}

Traditionally, extended school year is thought to be a summer program that extends over the summer months during the time schools are closed (Bar-Lev, 2004; Browder, Lentz, Knoster, \& Wilansky, 1988; Margolis, 2005). However, extended school year services may be a time when teachers merely make periodic contact with individuals with disabilities. It can also encompass assisting parents as they attempt to help their children at home. Additionally, 
extended school year services may include special education and related services such as physical therapy, occupational therapy, and speech.

In certain communities, Head Start, private preschools, day care, park district programs, YMCA and YWCA programs, and summer day camps have been discussed as possible places to deliver extended school year services. Brainstorming on this issue has provided some communities with more placement options than they originally thought they had (Wischnowski, 1999, p. 2).

\section{Legislative History of Extended School Year Programs}

There are two laws that are relevant when considering extended school year. They are Individuals with Disabilities Education Act (IDEA) and Section 504 of the Rehabilitation Act. IDEA is a law that was originally enacted in 1975 as the Education For All Handicapped Children Act (McMahon, 1994; Palmaffy, 2001). In the 1990 reauthorization, its name was changed to the Individuals with Disabilities Education Act (IDEA) but its purpose remained the same: to provide all students with disabilities access to a free, appropriate public education. It is important to note the wording of "appropriate”, which implies not best possible. “Appropriate” can be used to justify why extended school year is not required. If most students lose skills over the summer months, then students with disabilities may be no more affected than all children. Extended school year provisions may in effect go beyond our notion of free, appropriate public education (FAPE) (Bar-Lev, 2004; Bureau of Instructional Support and Community Services, 2002; McMahon, 1994; Olmi \& Walker, 1995; Palmaffy, 2001). 
The 1999 IDEA regulations define extended school year services for the first time. According to this definition, these services are special education and related services that are provided to a child with a disability beyond the normal school year of the public agency, in accordance with the child's IEP, at no cost to the parents and child; such services must meet the standards of the state education agency (Potter, 1999, p. 1).

In the past IDEA did not address extended school year issues specifically but, it did so by implying that special education programs must meet the needs of the individuals with disabilities. If extended school year is part of what is needed for an "appropriate” education, the mandates of IDEA became necessary leverage when determining eligibility criteria (Copenhaver, 2004; Katsiyannis, 1990; Osborne, 1995).

Section 504 of the Rehabilitation Act is the first federal civil rights law that protects the rights of persons with disabilities. The law states:

No otherwise qualified handicapped individual in the United States...shall solely by reason of his handicap, be excluded from the participation in, be denied the benefits of, or be subjected to discrimination under any program or activity receiving federal financial assistance (Palmaffy, 2001, p. 5).

If a person has a physical or mental impairment that limits a critical life activity, reasonable accommodations must be made. A critical life skill is any skill that the IEP committee deems to be critical to an individual's progress educationally (Olmi \& Walker, 1995; Prince George County Public Schools, 2002). This would include skills necessary for obtaining independence and self-reliance. "While 180 days of school may be adequate for some 
handicapped students, it may not be adequate for others...” (Bar-Lev, 1998). In this way Section 504 provides the rationale for extended school year for some students with disabilities.

The question becomes, what have states done to respond to the needs of students with disabilities in terms of extended school year programs? In a study conducted by Alper and Noie in 1987, it was found that court rulings have greatly impacted 49 states as they now have statutes and polices relating to extended school year services (Katsiyannis, 1990; Olmi \& Walker, 1995). However, there is considerable variability across states and school districts. While provisions have addressed extended school year services, at this time, there is no federal or state law providing eligibility criteria. In fact there are a very limited number of standards which are currently in existence, and even those are different, not only among states, but between school districts and counties (Palmaffy, 2001; Rapport \& Thomas, 1993; Sharpton, Sexton, Luster, \& Long, 1993). Courts have "provided nothing more than a list of general criteria, with no guidance or even suggestion of preferred tests, cutoff scores, measures, or significant levels” (Rapport \& Thomas, 1993, p.18). The Office of Special Education Programs (OSEP), of the United States Department of Education, regularly monitors each state’s extended school year policies and implementation procedures (New Jersey Department of Education, 2002).

In a pilot study conducted during the summer of 2002, randomly chosen county special education coordinators in West Virginia were asked, via telephone interviews, several questions regarding extended school year services offered in their districts. The questions ranged from general information about the county itself to very specific inquiries about eligibility criteria, delivery of services, and effectiveness of their particular program. As a whole, the administrators were very forthcoming and candid in answering the questions. Answers varied as 
to how each county handles extended school year services. However, when asked about factors for eligibility criteria and who makes the decisions, administrators gave the "politically correct" answer. "Eligibility is determined in the IEP meeting based on data kept by the teacher regarding regression/recoupment” (Bonnett, 2002). During the pilot study, it became apparent that in the past, administrators were reluctant to earmark special education funding for extended school year programming. Even now, they are strictly following the rulings of the court and are not willing to do anything above and beyond what is legally required.

\section{Judicial History of Extended School Year Programs}

Two early court cases, laying the foundation for extended school year litigation, are Pennsylvania Association for Retarded Children (PARC) v. Commonwealth of Pennsylvania (1972) and Mills v. Board of Education of the District of Columbia (1972) (Katsiyannis, 1990; Olmi \& Walker, 1995; Palmaffy, 2001; Underwood \& Mead, 1995). These two cases, in essence, guaranteed the right of students with special needs to attend public schools. The cases also established that the Constitution's guarantee of equal protection and due process which prevents schools from excluding students with disabilities. Additionally, parents were provided a range of methods for challenging the decisions made by schools regarding their child's educational programming. Probably the most important provision these cases established is the guarantee that cost is no excuse for failure to properly educate students with disabilities. As a result of these two cases the framework for future litigation involving students with disabilities and extended school year was built. In other words, if extended school year is seen as a necessary component of a free, appropriate education (FAPE), the cost should not be a deterrent. A landmark court decision, Armstrong v. Kline (1979), was handed down in Philadelphia 
on June 21, 1979 when provisions were made for extended school year programs (Kabler, et al., 1983; Katsiyannis, 1990; Underwood \& Mead, 1995; Wilds \& Liacopoulos, 1988). In this case, five children with severe disabilities and their parents filed three class action suits that were later combined for trial. The district court found that students with severe disabilities experienced significant regression during long breaks in schooling, especially during the three-month summer break, and time required to regain lost skills was substantial. The judge noted that, while it is common for most school districts to provide a summer school session, it is usually at a fee to the parents. Armstrong v. Kline, 1979, argued that extended school year programming should be offered under the free, appropriate public education law in which "free” is defined as "at no cost to parents”, thus making a mandated 180-day school year in violation of a child's right to a free, appropriate public education. The most effective argument made in this case was the loss or regression in essential skills and behaviors of students with disabilities when education is interrupted. Along with this argument, the point was made that a substantial amount of time was needed to regain those losses (ESY Talk Quotes, 2002; Underwood \& Mead, 1995; Wilds \& Liacopoulos, 1988). If time off from school causes regression and the student has an inordinate recoupment time, extended school year is considered to be part of what is appropriate (Browder et al., 1988; McMahon, 1994; Osborne, 1995).

Regression in the child's past does not have to be proven to make the case for extended school year. Prospective information, established by expert opinion based on professional individual evaluation, can be considered when determining the need for extended school year. On July 15, 1980, Armstrong v. Kline became known as Battle v. Commonwealth in which the courts upheld the decision that regression, due to long interruptions in education, violated the 
requirements for an appropriate education for children with severe disabilities (Alper \& Noie, 1987; ESY Talk Quotes, 2002; Katsiyannis, 1990; Underwood \& Mead, 1995). The issue at the heart of the court cases is whether or not extended school year is necessary to provide for the maintaining of skill levels and decreasing recoupment time.

An important case dealing directly with extended school year is Education of Norwich (1983). The plaintiffs in the Norwich case consisted of one child with autism and one child with hyperactivity and neurological impairment. This case established that the school district is directly responsible for locating and arranging appropriate summer programming for students with disabilities (ESY Talk Quotes, 2002; Underwood \& Mead, 1995; Wharton, Aldhizer and Weaver, 2003). This case took summer programming a step further by requiring school districts to provide out of district transportation for students if needed.

\section{Eligibility for Extended School Year Programs}

Although the question of eligibility for extended school year programs is problematic, criteria have been suggested that are supported by judicial decisions. They include individual need, nature and severity of the disability, educational benefit, self-sufficiency/independence, and regression/recoupment (Bar-Lev, 1998; Bodkins, 2002; Copenhaver, 2004; Kabler et al., 1983; McMahan, 1994; Rapport \& Thomas, 1993). The attainment of self-sufficiency has been a key issue in the question of extended school year eligibility since independence is often the primary objective in the lives of individuals with disabilities. A study conducted in 1983 by McMahon analyzed teacher ratings on ten areas of self-sufficiency for 26 extended school year students attending a private six week summer program. McMahon found that teachers felt regression did occur when instruction was interrupted, but there was improvement when it was 
resumed (McMahon, 1994; Pinkerton, 1990).

Individual Need. The ability of the child's parents to provide educational structure at home and the opportunity for the child to interact with non-disabled children must be considered (Missouri Department of Elementary and Secondary Education, 2002). In federal court rulings, Johnson v. Bixby (1990) and Battle v. the Commonwealth of Pennsylvania (1980), it was determined that consideration should be given to the ability of the parents to provide educational structure at home. This is an important issue when deciding whether or not a child is eligible for extended school year services. "If parents can provide the proper structure at home, the regression and recoupment issue will not be as severe... Perhaps the student's utilization of a computer software program will be sufficient to maintain a critical skill” (Bar-Lev, 1998). The IEP committee, after deciding the parents are not willing or able to provide structure at home, can decide to recommend extended school year services.

A study by Barton, Johnson, and Brulle (1986, as cited in Alper \& Noie 1987) evaluated the effects of extended school year on students with severe and profound mental retardation, matching subjects by age, sex and handicap. The control group received no summer school and the experimental group attended a six week summer program. Everything else being equal, the extended school year students acquired new skills and the skills were additive to those gained during the regular year. The control group had not caught up to the extended school year group by November of the following school year (Alper \& Noie, 1987). A child's individual need for extended school year programming should be determined annually at the IEP meeting (McMahan, 1994; Palmaffy, 2001), since children may require education in addition to the regular 180-day school year in order to receive an education that is appropriate and meets his/her 
unique needs.

When determining need for extended school year, one issue everyone agrees on is that all states must notify parents that a child may be eligible for extended school year programs. This is sometimes problematic because, while administrators are supportive of the idea of extended school year, they are also reluctant to inform parents of rights because of cost, low federal support, declining state aide, and budget cuts (Copenhaver, 2004; Rapport \& Thomas, 1993). Once parents have been notified, information is gathered about the child's current status educationally and an Individual Education Program (IEP) conference is held. Members of the team face the difficult task of determining if the student is eligible for extended school year. The notion is that most students with disabilities do not need extended school year, but provisions must be made for those who do. School districts cannot have any policies that would preclude consideration of extended school year for any given student (Osborne, 1995). If parents do not agree with the decision of the IEP committee, they have the right to appeal to an impartial hearing officer or state level review official (Rapport \& Thomas, 1993).

When determining individual need, issues that have had a major impact on today’s debates about extended school year should be examined. One of the major controversies occurs when there is disagreement over what is "appropriate”. As a result of the court case in the Board of Education of the Hendrick Hudson School District v. Rowley, 1982, the U. S. Supreme Court, recognizing the need for consistency in determining criteria for extended school year, developed a two-prong test to determine if extended school year might be appropriate in various cases. In the first prong, one must determine if the IEP has been developed in accordance with the procedural requirements of the Individuals with Disabilities Education Act (IDEA). In the 
second prong, one must determine if the special education program described is reasonably calculated to confer educational benefit on the student (Osborne, 1995). This two-pronged test can be applied to decisions about individual need for extended school year.

Nature and Severity of Disability. The nature and severity of the child's disability is also important to consider. Children with severe and multiple disabilities are more likely to be eligible for extended school year programs. According to a summary of extended school year cases between 1979 and 1990 children with the most severe handicaps were typically the ones who received extended school year (Kabler et al., 1983; Rapport \& Thomas, 1993). Disabilities most prevalent in the summary included profound mental retardation, severe autism, neurological impairment, and children with multiple disabilities. Extended school year litigation has also been applied most often to individuals with moderate and severe handicaps, because these individuals show a faster rate of regression (the lack of maintenance or loss of skills) and a slower rate of recoupment (getting back that which was lost) (Bureau of Instructional Support and Community Services, 2002; Copenhaver, 2004; Pinkerton, 1990).

Regression/Recoupment. "Children learn best when instruction is continuous” (Cooper, 2003). It is important that regression/recoupment deficits be determined for each child regularly. Students, who cannot maintain critical skills including self-help, socialization, appropriate behavior, and community integration, must be afforded the opportunity to receive uninterrupted individual instruction. Relevant skills should be determined by the IEP committee, based on data collection provided by the teacher of the child. While there is no mandated way to collect data, practical examples of day to day assessments regularly used by the child's teacher are considered best (Browder et al., 1988). 
One other important factor that IEP committees must consider is if the child will be denied access to other children without disabilities if extended school year opportunities are not made available (McMahon, 1994; Pinkerton, 1990). If the IEP committee has determined that the child will spend part of the day interacting with non-disabled peers in extended school year, then this argument becomes a basis for extended school year placement.

Another major issue in the extended school year debate is the question of cost. Once an extended school year is made part of the IEP, it must be provided at no cost to the parents.

In Georgia Association for Retarded Citizens vs. McDaniel (1983), the court ruled that a school system cannot use a 'lack of available funds' argument to deny extended school year services to a child with a disability. A school system must look at the child's needs, rather than its budget, when determining summer services for a child (Kraft, 1999, p. 2).

Extended school year based on the definition of FAPE implies that the range of programs can be large, based on the child's IEP. Services can be defined as anything from physical therapy, to summer camp, to other non-classroom activities if the child’s primary need for extended school year is related to socialization skills (Oregon Advocacy Center, 2002; Valley News, 2004; Vinluan, 2005). Clearly, FAPE for a child with behavior disorders must mean participating in activities that help promote socialization and decision making skills. Extended school year services may include home instruction or consultation, individual or group instruction, support services, and recreational services that provide for the maintenance of identified IEP goals. Physical, speech, and occupational therapy are also types of services offered. Certain communities use Headstart, private preschools, daycare, and YMCA programs 
to deliver extended school year programs. (Copenhaver, 2004; New Jersey Department of Education, 2002).

Although the literature is limited, it suggests there is a great need for more specific guidelines concerning eligibility criteria for extended school year services. The types of services and the way they are implemented are a growing concern as to the appropriateness and effectiveness of extended school year programming. Further research should be focused on these issues in order to present a more accurate assessment of services required.

No matter how available services are structured, examination of youth programs suggests there are components which make them successful and may imply how extended school year programs might best be structured. Essential components, in order to be productive and successful, first include the fact that children must benefit from the services. Second, there must be family involvement. Third, there must be community involvement. Finally, there has to be a commitment from the school system so that extended school year services are well-integrated with services offered during the school year.

\section{Essential Components For Successful Extended School Year Programs}

Child Centered. Perhaps the single most important component for any social or educational youth program is that it is child centered (Cotton, 1997). When programs are successful, the children achieve better academic progress, have improved school outcomes and build stronger family ties (Kraft, 1999; Maynard, 1997). According to Richard Riley, “Too many of our young people are growing up disconnected...500,000 young people drop out every year” (Riley, 1999, p. 24). When there is a connection between the program and the child, there is a very high impact on learning. When the components begin to come together, there is child 
benefit (Cotton, 1997).

Family Involvement. Family involvement can include everything from shared governance to shared funding. By involving the family, programs become comprehensive and intensive. For extended school year programs to be successful and beneficial, they must be flexible by engaging families and "going beyond the rigid rules and procedures that keep services fragmented and overlapping” (Copenhaver, 2004; Cotton, 1997). Programs must also be culturally and ethnically competent (Anderson, 2000). Provisions need to allow for the diversity of the families receiving services.

One successful youth project which includes family involvement is the Total Village Project which was developed by Stan Maynard, Department of Education at Marshall University, Huntington, West Virginia. Their objectives include parent attendance at meetings and activities with quality and quantity parental involvement (Maynard \& Howley, 1997). This project includes a family center, family services, parent-teacher action teams, and assistance to teachers.

Another successful youth program is the Teacher-Parent Partnership for the Enhancement of School Success. This program includes training activities for teachers, parents, and children. It also encourages intensive parent involvement activities. Home-school workers and summer enrichment activities play a large part in this project (Maynard \& Howley, 1997).

A final example of family involvement is Even Start, which builds on the role of the parent. In the Even Start project, parents are seen as communicators, supporters, learners, teachers, advisors, and advocates (Maynard \& Howley, 1997). Parents attend school with their children. While at school, parents are given an opportunity to improve themselves. Tutors are available to help with GED requirements. Additionally, parents have an opportunity to observe 
and model appropriate parenting skills.

Community Involvement. Once children and families are involved in extended school year programs, communities must be added. "Community support expands parent involvement, creating a revitalization of schools and ...economies” (Maynard \& Howley, 1997). Communities must respond to the local needs. Community partners can help school districts enhance their school programs by helping to focus on school-linked services supporting academic achievement (Public Education Network, 2002). This can be achieved when communities help undertake essential programs.

It is important to note that projects bringing all aspects of the community together can be instrumental in improving schools and the economy.

For example, in a collaborative after school arts program, classroom teachers and visiting artists work together to teach African drumming or book making. Through the program, classroom teachers can observe other professionals working with youth, thus seeing their students in non-classroom settings where they may have new opportunities to display their talents. Similarly, the visiting artists can learn from classroom teachers. For instance, they may consider building their individual lessons into a sequenced curriculum or learn new ways to teach reading. (Honig et al., 1999, p. 11).

When these components are brought together, there is a renewed investment by community members (Maynard \& Howley, 1997).

People are recognizing what so many of you have recognized for years- that our public schools really can be 'centers of community' for entire neighborhoods. This is particularly important in some of our inner city neighborhoods where public school is the 
only 'anchor' that holds the community together (Riley, 1999, p. 7).

This statement is true for rural areas, which are often times isolated, poverty stricken, and lacking in job opportunities. In order for schools to become these “centers of community,” there must first be a commitment on the part of school districts (Cotton, 1997; Maynard \& Howley, 1997).

School Commitment. An important focus of the school district should be social, cultural, and health development of children. Schools must learn new ways to work with outside agencies, community members and parents, to share space, information, and goals (Lockwood et al., 1996).

It is important that educators and school boards reach out to the entire community in planning the use of the schools by the community for extended school year programs and after school activities such as GED courses, adult education and literacy (Riley, 1999). But schools must go even further by providing direct and indirect support for parents. Schools must be bonded to families and communities (Lockwood et al., 1996).

Schools are the largest public program for children and are necessary for helping to improve the condition of children (Herrington, 1994). However, they must become "full-service schools”, a term coined by Joy Dryfoos to encompass school-based health centers, youth centers, community schools and family resource centers. Schools should be “a comprehensive, one-stop educational service center” (Lockwood et al., 1996).

When agencies work with the schools, there is a better chance of preventing a child who falls in the "gray areas" from being left behind (Lockwood et al., 1996). This is because there is better monitoring of grades and absences since there is collaboration among agencies. When 
agencies and schools work together, more resources can be utilized. Also, more support is provided for children. More and more, communities are being used as important learning resources for after-school enrichment.

Initiatives such as The Child and Adolescent Service System Program have provided evidence that collaborations between agencies and communities can lead to improved outcomes for children and their families (Anderson, 2000; Garland \& Osborne, 2000). This program emphasizes how to best provide services for children with disabilities and their families.

Children are in more stable environments and there is a higher level of expectation. Families do not feel they are left out of the educational process. Added support helps families to follow through with the collaborated family improvement plan, thus improving the overall self-esteem of the family. Family relationships become more stable.

During the past 15 years, there have been several initiatives for coordinating agencies, schools, children, and their families (Anderson, 2000; Garland \& Osborne, 2000). The Dawn Project is a good example of social and educational programs working together. The project provides a system of community-based services for children and their families. (Anderson, 2000). Started in 1997 in Marion County, Indiana, as a program for at-risk children, it expanded to include their families. Service coordinators help to develop multi-agency service plans for families. These plans enhance strengths of the family and address the needs of parents and children.

Another example is SpecialCare Outreach, a project which focuses on developing a link between interagency planning groups and families of young children with disabilities. “The SpecialCare model of training builds on traditional care giving roles and skills, expanding care 
givers' knowledge and level of comfort so that care givers are willing and able to extend their traditional roles to care for children with disabilities” (Garland \& Osborne, 2000, p. 1).

As a result of these initiatives and others like them, there has been a realization that parent involvement results in greater child achievement.

Schooling improves when a variety of adults share their talents and model successful strategies of life management. Moreover, when community and business organizations have a visible presence in classroom life, students are more likely to see a meaningful connection between their studies and their eventual success in the workplace (Maynard \& Howley, 1997, p. 2).

There is power in school and community collaborations (Bar-Lev, 2004; Focus on Schools and Communities, 1999; Vinluan, 2005); however, with power there is also a responsibility to ensure the needs of the children are being met. Policies and structures must be in place for collaborations to be successful. There must be commitment from schools, communities, and families. Challenges must be addressed and solutions implemented. It is important to discuss policies and structures in relation to comprehensive community services as they appear to be essential to successful extended school year programs.

One such program that has "opened the doors" for community collaboration during the summer months is Energy Express, an initiative designed to address the nutritional and literacy needs of low income elementary-age children during the summer months (Butera, Bonnett, McMullen, Pae, \& Richason, 1999). In Energy Express, a community collaborative made up of school system personnel, community service agencies, local businesses, and members of the community work together to generate local funding to match state, federal, and foundation 
monies for the summer program. The collaborative is a deliberate attempt to create collaboration between schools and community agencies.

Piloted in 1994, Energy Express began with two sites and has added sites most years of the program’s existence. In 2001 there were 87 sites across West Virginia (Butera et al., 1999). According to Ruthellen Phillips, State Energy Express Director, even though the sites are located in county schools, “Energy Express is not school!”(personal communication, June, 2000). Energy Express is a purposeful, child centered program that incorporates community, school, and family. Each site includes a site coordinator, a volunteer coordinator, five to eight college aged mentors, and six to eight multi-aged children in each mentor group. The children and their mentors create print rich environments, engage in read alouds, and build lasting relationships. The games are noncompetitive and the meals (breakfast and lunch) are served family style with the children. The curriculum is place-based and each week has a special theme: Friends, Family, Myself, Home, Community, and Making My World A Better Place. A representative sample of the children at each site are given a pre and post Woodcock-Johnson III Reading Achievement sub-test to determine maintenance and/or improvement of reading skills over the course of the program. Since 1998, the Energy Express evaluation team has reported that 70\% of those children tested either maintained or improved their present level of reading ability. These gains are evident in the regular education population attending, and in children with IEPs who demonstrate improvement similar to their peers (Butera, 1998; Butera et al., 1999; Butera, 2001; Bonnett, 2002a).

In some instances, Energy Express serves as an extended school year program for children with disabilities in the community. Case studies conducted during summer 2002 at two 
Energy Express sites provide insight into how local programs address the needs of children with specific learning and behavior deficits. In interviews, site coordinators indicated that $30 \%$ to $37 \%$ of the children enrolled in their program were children with disabilities. They also reported making modifications needed for the child, taking into account the severity of each child's disability, the expertise of each mentor, and the child's individual education program. At each site, the site coordinator made choices concerning how to handle disclosure of information concerning the students with disabilities. These decisions reflected the personalities of each site coordinator and the climate they were trying to establish at that particular Energy Express site.

The coordinator at the first site felt the mentors needed to know which students had IEPs in order to prepare mentors for possible problems. She felt that, once the mentors were familiar with the IEP's of their students, they would be better equipped to handle their particular problems. Her view of children with disabilities was a more "classical” view. It was her opinion that the problem was inherent in the child. She was very vocal about the various "labels" of the children and often described children as, “ADHD”, "BD” or "LD”.

The coordinator at the second site stressed that the mentors not know which students had IEPs. In this way, she felt the mentors were less apprehensive and not biased. "I'm always afraid the mentors will be more apprehensive than necessary. I am also concerned they will treat those students differently.” When there was a problem, the site coordinator and the mentor sat down to discuss the issues. It was only then that the mentor was made aware of the contents of a particular child's IEP. The site coordinator felt the problems of the children were more environmental and that if the mentors were not aware of the problems and were not looking for them, they may not arise. "Labels” were not important to her, each child was an individual and 
was treated accordingly (Bonnett, 2002a).

Energy Express is an established program that has been instrumental in demomstrating the importance of local policy when determining how to implement a successful extended school year program. This community and school collaboration has been documented as a successful child centered initiative and based on over five years of evaluation collection, it can be stated that Energy Express has successfully demonstrated all the necessary components for an effective summer program (Butera, 1998; Butera et al., 1999; Butera, 2001; Bonnett, unpublished manuscript, 2002a).

\section{Policy}

For the purpose of this literature review, policy is defined as a prescribed course of action based on values which are positively or negatively reinforced by key actors. "The actors range from governors and other 'insiders' at the state level to school boards, and special interest groups” (Hazi, 1998, p. 975) .

Policy, in terms of education, basically focuses on such items as finance, administration and curriculum. However; given the need to take local circumstances into account, policy needs to be redefined as "to operate on a community level and, thus, engage the multiple resources and supports available in a school's neighborhood” (Honig et al., 2001, p. 1022). These resources and supports include, but are not limited to, public libraries, local businesses, government agencies, and churches. New policies must include "protocols and guidelines within the school system that would help coordinate and link community-based services” (Public Education Network, 2002). Schools and communities must organize to develop policies which would be the most beneficial to both children and families within the community. Extended school year 
programs must reflect this type of policy development (Issues in Education, 2001).

Although virtually all school systems follow policies, there must be new policies implemented to revamp the organizational structures of schools and modify present curriculum standards so as to provide guidance to extended school year programs (North Central Regional Educational Laboratory, 1996, p. 1).

There are many outside factors which must be taken into consideration when looking at what makes extended school year programs successful. Home environment, teacher expectation, student attitude and community perspective all play major roles. When considering this issue, policymakers tend to focus more on the formal education system without looking at the variety of resources and supports within the realm of the community (Honig et al., 2001).

It is interesting to note many projects and school-community initiatives are successful on local levels. Additionally, there are state-initiated efforts in which local services are asked to collaborate, but no consistent guidelines which state agencies and policymakers can follow (Crowson \& Boyd, 1993). The problem policymakers face now is sifting through the information and making it available to schools, parents, agencies, and communities who plan extended school year programs.

Policies which are mandated should also be funded. In fact, it is impossible for schools and communities to collaborate without policies which will provide funding for educational and social services (North Central Regional Educational Laboratory, 1996). One example of policy involving school-community partnerships is the Kentucky Education Reform Act (KERA) which was designed to improve the academic performance of students by giving funding to schools comprised mainly of children from low-income families. Centers have been funded to improve 
student achievement in non-academic ways. The centers are located near the school and address components such as after-school child care, health, and education services for new and expectant parents, health services, parenting skills, referrals to social services, summer and part-time jobs for youth, substance abuse services, and family crisis counseling.

The centers all follow the same basic guidelines and upon examination, it was found that the centers are working well and are considered to be effective. Teachers have reported school attendance gains and greater achievement among students who used the services of their local centers. Additionally, students complete more homework, follow directions better, remain on task longer, and are more likely to obey school rules (Smrekar, 1994). These sorts of initiatives provide details regarding how extended school year programs might be organized.

Overall, the literature indicates there is a lack of clear and consistent policies, at both state and federal levels, designed to help agencies, schools and communities combine their services to provide the extended school year services mandated by IDEA. The lack of policy appears to stem from the fact that, in the past, each of the involved organizations worked alone. There was little or no collaboration due to reluctance on the part of everyone involved.

Of course, schools and community agencies cannot embark upon these endeavors without enlightened social policy that re-engineers funding of educational and social services, revamps school organizational structures, modifies curriculum standards, and changes data gathering and reporting mechanisms to aid decisions related to accountability (North Central Regional Educational Laboratory, 1996, p. 1). 


\section{Structures}

According to the literature, once policies are put into place, the focus needs to turn to structures of available services. "Communities differ in their capacities to respond to the needs of youth” (Butera et al., 2000, p. 30). Opinions are varied as to the types of structures needed, but all agree that collaboration is more successful if community representatives are a part of a participatory decision-making structure (Cotton, 1997; Lockwood et al., 1996). Involving all parties in the beginning helps to establish ownership of the project. In turn, each agency is able to express their needs and wants in a non-threatening atmosphere.

Nine types of structures can be described in successful projects. Some may involve only one type of structure while others may involve a combination. One such structure is the lead agency. In this structure, one agency or organization is the primary liaison for all activities. The lead agency develops and coordinates community-school projects.

Coordinating councils comprise another type of structure. In these councils, information is distributed and services are coordinated among delivery agencies or organizations. Various organizations are responsible for particular sections of a project. In some instances, professional advisory committees are formed to give professional advice. Only those having legitimacy in the community are part of the committee. Members of advisory committees meet with school and community representatives to discuss activities.

Steering committees are used to govern or plan for a larger collective body. The steering committee makes general decisions concerning projects. Once the steering committee comes to a common consensus, they present their ideas to community organizations for approval. A task 
force implements a particular program activity. Task force committees are usually comprised of community and professional members. They help improve coordination among agencies which provide various services.

Another group is categorized as "grassroots”, which is an informal, voluntary structure initiated by residents to respond to one particular concern or condition. They build "upon people's commitment to their own turf and translate the abstract concept of community into concrete reality” (Cotton, 1997, p. 12). Networks are loosely structured and provide linkages between groups and organizations. They are similar to "grassroots" in that they share a commitment to a community issue. There are no formal leadership structures. Networks share ideas and strategies.

Coalitions are formal alliances which work together for a common goal. Coalitions include organizations, agencies, communities, and schools. They are usually disbanded once the common goal has been achieved. Co-production organizations are formed when city government and neighborhood organizations divide responsibility. Delivery responsibility is divided into component tasks. Tasks are then given to each via service contracts (Cotton, 1997; Lockwood et al., 1996). These structures provide the framework through which schools and communities may plan for extended school year programs.

\section{Challenges}

In the process of collaboration, there are barriers to be removed and challenges to be met. Singular perspectives, the language of definitions, conflicting eligibility criteria, competition for clients, fragmented delivery service, family problems, parent and community response to interventions, and a basic lack of information are challenges likely to be encountered when 
designing an extended school year program. Perhaps the greatest problem is that of singular perspectives. Each organization has a limited view of their clients and their needs. An excellent example is described when considering the plight of a high risk teenager.

An educator sees a STUDENT in danger of dropping out; A health-care provider sees a PATIENT at risk of having a low-birth weight baby; A social-service worker sees a CLIENT who may require public assistance; A juvenile justice worker sees a potential RUNAWAY; An employment specialist sees a TRAINEE needing multiple services; and A community or religious leader sees the troubled OFFSPRING of a personal friend (Cotton, 1997, p. 44).

This can lead to a lack of understanding of how other organizations are required to operate.

The language of definitions used to identify children for services can also interfere with collaboration. A child who has been identified with a learning disability may qualify for one program but be excluded from receiving services in another program because of the very same identification (Anderson, 2000).

Additionally, many times there is confusion over conflicting eligibility criteria and confidentiality requirements (Cotton, 1997). When agencies are unable or unwilling to compromise over these issues, children are caught in the middle. Many times organizations are in competition with each other for clients. In such situations, funding is contingent upon the number of clients served. This can cause conflict between agencies. New money must be brought in as well as redistributing exist funds and staff (Lockwood et al., 1996).

In many instances, the delivery system of services is fragmented and follow-up becomes nonexistent. Outside agencies rarely initiate contact with schools to ensure a client's individual 
plan is being followed. On the other hand, school systems, which in the past have isolated themselves, are reluctant to bring in outside agencies. Many youth organizations and schools miss opportunities to collaborate in ways which are essential to youths' learning (Honig et al., 1999). Often, if schools are willing to work with other agencies, there is not enough information or access to needed services for children and their families. There are not enough ways for school personnel to refer students for services (Public Education Network, 2002).

Children often face non-academic problems which impede their achievement, requiring collaboration between parents and community agencies for interventions such as pregnancy or counseling (Cotton, 1997). In many communities these and other controversial topics are felt to be family problems and should be dealt with on the family level. For this reason, support systems may be minimal.

The question of how school districts plan policies and employ structures to implement extended school year programming has been investigated (Bonnett, 2002b). In order to address the issues surrounding extended school year services, a random sample of 19 West Virginia Special Education Administrators (from a pool of 55) were surveyed to determine how they provide extended school year services for children with special needs in their county.

The results of the survey indicate that eligibility for extended school year is generally contingent upon two factors. The first is regression/recoupment, defined as administrators/IEP team member's judgment about the academic skills that a student may lose whenever there is a break in schooling and the amount of time it takes to regain that knowledge. Second, the severity of a student's disability generally determines whether or not a student is eligible for extended school year services. One county director reported, “Only those students who have 
been identified as severe and profound meet our definition of eligibility.”

In the study, data collection to determine eligibility varied greatly from county to county. Since there is no specific way mandated to collect data, inconsistencies arise and most participants agreed, there is a need for a more reliable measure of regression/recoupment. All agree that extended school year eligibility criteria guidelines lack a clear, specific definition. Each county acknowledged interpreting the guidelines differently.

According to one special education director, "Regardless of eligibility, parents still refuse...and they can if they want to.” The survey indicated that some parents of children with special needs do not want to enroll their children in extended school year programming. Survey participants stated that while parents have the final say as to whether their child attends extended school year programming, they often do not understand what extended school year is all about. As one director stated, “They think it’s summer school and they don’t want their kids in summer school. It's not; it’s an entirely different realm.”

Getting the parents more involved would be beneficial to all those concerned, according to the study. One county director reported, "There are a lot of children who qualify but the parents choose for them not to participate. It interrupts what they have planned for the summer.” On the other hand, there are parents who want their children eligible for extended school year services. Parents are viewed as the ultimate decision makers. One special education director reported, "It's not worth trying to fight them.” Another stated, "If the parents request extended school year services, we do not honor the request, only when the child is eligible.” (Bonnett, 2002b).

This study was conducted as a pilot to the current study. At issue is how school districts 
plan for extended school year services. Extended school year may differ from regular school in that it gives students an opportunity to learn differently and get involved with more "hands on" activities. One county director explained, "There are more things to do in the summer, which you can’t do in the regular classroom.” Since extended school year is based on individual needs, it may be easier to provide students with practical application. Teaching social skills to students with behavior disorders could be best taught "out and about” the community during extended school year. Summer recreation, public library activities, and community programs such as Energy Express provide evidence they could be incorporated into an extended school year program by simply having a special education teacher available for consultation when necessary (Copenhaver, 2004). Another county director reported, "Kids need a different experience than regular school.”

There are also those students who qualify for extended school year services who need a structured program that specifically focuses on student needs. As reported by one special education director, “It’s more school like...they need a more structured setting.” All administrators in the study agree, "Extended school year is definitely needed for certain types of our students.”

Finally, participants in the study discussed the expense of extended school year services. “It's expensive. It costs more than other summer programs.” As with other state mandated programs, extended school year has limited resources, which at times determines the type of programming a county offers. While most county special education directors interviewed were very careful not to admit lack of funding as an issue that dictates the type of services being delivered in their county, it was alluded to on several occasions. 
Could variations in duration, frequency, and length of daily programs be directly related to funding? Are the student's needs being met? Results of this study clearly indicate that programs differ widely in their response to student need. According to this preliminary study, extended school year programming is dependent first, on funding, and then on what the parents want and finally, what the student needs (Bonnett, 2002b).

There is no doubt that collaboration to improve extended school year services can work. “There is perhaps no better alliance than one that draws schools, family, and community into a shared responsibility for mentoring and raising future citizens” (Focus On Schools And Communities, 1999, p. 1). There are more and more successful community partnerships being built.

It sounds remarkably simple. It is remarkably difficult. In order to provide... comprehensive and cohesive services to at-risk children and their families...the school and social service bureaucracies must over-come years of differing traditions. People who have never worked together must form teams. Schools must open their doors to outsiders, and social service agencies must relinquish control of some activities (Cotton, 1997, p. 33).

Clearly, the literature demonstrates a need for changes in collaboration between agencies, communities, and families in planning and implementing successful extended school year programs.

Federal law mandates students with disabilities, who meet certain criteria, be given an opportunity to continue educational services beyond the 180 day school year. Extended school year for students with disabilities has been the subject of debate for more than two decades 
(Copenhaver, 2004; Katsiyannis, 1990; McMahon, 1994). This debate has been fueled more by ideology than research. The literature on extended school year is scant and noteworthy for its lack of empirical data. The rationale for extended school year centers on the idea that students with disabilities require more time to regain skills which are lost during the summer months or other school vacations. However, school districts are reluctant to identify students who would be eligible for extended school year because of the expense that would be incurred.

Extended school year programs for children with disabilities must be IEP driven. However, the need to include community, family, and school in extended school year programs also seems apparent. Current issues regarding child benefit, eligibility, funding, and interpretation have left school districts struggling to provide effective extended school year programs. Key stakeholders are confused and uncertain as to the framework of an extended school year program. Regardless, student needs must be the main focus for extended school year programs. This research is designed to deepen our understanding of how extended school year programs are planned, developed, and implemented in order to best meet the needs of the students and the communities which they serve. 


\section{Chapter 3}

\section{Method}

In this research, descriptive case study has been chosen as method. This type of research is especially effective for the research project because it takes into account people’s perceptions and belief. Since the extended school year pilot study indicated many different ideas about the essential components of extended school year programs exist descriptive case study will be useful in establishing the perspective of practitioners about extended school year.

The purpose of this study is to describe the perceptions of key stakeholders about extended school year in the state of West Virginia by examining two cases in detail. Three questions will guide the research:

1. What are the beliefs of key stakeholders (parents, teachers, administrators, and service providers) about extended school year? How do these perceptions compare/contrast with one another?

2. How do the practices of extended school year programs relate to the essential components of a successful summer program for children with special needs?

3. What is the relationship between the beliefs of key stakeholders and the practices implemented during extended school year programming?

According to the literature on extended school year, the federal guidelines are vague and confusing. School districts across the state are mandated through IDEA (2004) to provide this service; yet, the courts have been reluctant to establish specific guidelines, which lead to little clarity in the interpretation of this policy. 
The current study will build on the pilot study by closely examining extended school year services in two West Virginia school districts. Careful attention will be given to selection, instrumentation, data analysis, and cross case analysis using case study design.

\section{Case Study Research}

The use of case study as an effective research tool has been debated. In fact, case study research has had long periods of use and equally long periods of disuse (Tellis, 1997a). During the last 20 years, several researchers have come to the forefront, many times facing criticism from their peers, to defend the use of case study methods. As a result, case study is being touted as an excellent research tool when investigating all aspects of a certain program (Feagin, Orum, \& Sjoberg, 1991). The methodology of case study has been developed to incorporate the thoughts and views of the different subjects involved while incorporating different types of data. Educational research has increasingly used case study to "maximize what can be learned, in the period of time available for the study” (Tellis, 1997a, p. 5).

Robert K. Yin, who has wide experience in case study methodology, has identified three types of case studies: exploratory, explanatory, and descriptive (Tellis, 1997b). In exploratory case studies, the data collection is completed before the research questions and hypotheses are defined. Questions can be dropped or added as the pilot study outcomes are evaluated. Explanatory cases are used in a more informal case study atmosphere and involve analyzing situations where the topic stays the same but the projects are varied. Finally, descriptive case studies take into consideration cause-effect relationships (Tellis, 1997b).

All three types of case study apply the requirements of qualitative research: describing, understanding, and explaining (Combs, 1995; Tellis, 1997a). While there is no single outline 
followed in case study research (Morse, Barrett, Mayan, Olson \& Spiers, 2002), case studies usually focus on developing an understanding of what is being examined. This focus will be employed in the current study.

Yin asserted there are four stages of case study methodology (Yin, 1994). First, a protocol must be developed. Once the protocol is established, the study itself is conducted. At the conclusion of the study, the evidence must be analyzed and finally, conclusions must be drawn, recommendations made and implications summarized.

In multiple-case studies, established protocol must be followed. The protocol determines the procedures and rules which are to be used during the case study. According Yin, 1994, established protocol is a "major component in asserting the reliability of the case study research" (Tellis, 1997a, p. 7). The protocol should include an overview of the project, the field procedures or sources of information, the case study questions, and a guide for the case study interviews (Flick, 2002).

The study is then conducted. There are several sources of data which can be utilized to complete the research process. They include: documents such as IEP's, interviews, direct observation, participant observation, and physical artifacts (Stake, 1995; Yin, 1994). Documents include everything from agendas to newspaper articles to letters. Interviews are important in case study. All types of interviews (i.e., open-ended, focused, or survey) are appropriate and tend to help corroborate evidence found in other sources (Flick, 2002; Patton, 2002; Tellis, 1997b). The purpose of qualitative interviews is to allow participants to express their individual perceptions in their own words (Flick, 2002; Patton, 2002).

Miles \& Huberman, (1994) suggest observations should not last longer than one hour and 
the frequency of the observations depends on the number of people and cases involved. "Field work should last long enough to get the job done-to answer the research questions being asked and fulfill the purpose of the study” (Patton, 2002). Observation data are obtained from field visits conducted throughout the duration of the study. Greater reliability is established when more than one researcher conducts the observations. A field journal is used to record experiences, reflections, thoughts, and feelings that might be notable when compiling and analyzing the data (Miles \& Huberman, 1994; Patton, 2002). When the researcher is also a participant, there are good opportunities for the collection of data, but care must be taken to ensure that the researcher does not cause changes in the outcomes of the study.

Once the data collection is completed, the evidence must be analyzed. The researcher must document that relevant evidence is in place. All interpretations of the analysis, whether in agreement or not, must be presented and finally, the most significant aspect of the study should be discussed.

Proof of reliability and validity is essential in case study research. Because qualitative researchers lack “the certainty of hard numbers and p values” (Morse et al., 2002), much effort must be made to ensure rigor. As a result of work in the 1980s, “Guba and Lincoln substituted reliability and validity with the parallel concept of 'trustworthiness', containing four aspects: credibility, transferability, dependability, and confirmability” (Morse et al., 2002). This criterion has been used to develop the standards which are now used to evaluate qualitative case study methodology.

\section{Selection}

While conducting the pilot study, it became evident that a variety of extended school year 
programs exist across the state of West Virginia. Therefore two case study sites from the study were selected to represent different methods of extended school year service delivery and different geographical areas within the state. A letter, followed by phone confirmation, was used to obtain permission to visit these sites. The letter also assured confidentiality and anonymity and described the intended use of the collected data (See Appendix A). Participants at each site were purposefully chosen for interviews. Participants included at least three parents, one special education teacher, one administrator, and one extended school year service provider. Six classroom observations were conducted during the program's duration.

Case Study Sites. Five potential case study sites which were representative of the variety of available extended school year programs in West Virginia were contacted for this study.

The criterion for judging when to stop sampling the different groups pertinent to a category is the category's theoretical saturation. Saturation means that no additional data are being found...nothing new emerges anymore (Flick, 2002, p. 64).

Babcock County, one of the contacted sites, is located in the northern panhandle of the state. Extended school year programming is based on the child's IEP. A portfolio is kept on every child with special needs to help the IEP team determine critical skill areas not achieved. There were several ways this county delivers extended school year services. There is a three week program for students who had been identified as having behavior disorders and/or mental impairments. This is a self contained program (the children stayed in the same place all day) and is similar to regular summer school. Another program is offered for five weeks, three times a week for one hour. These students' disabilities include learning disabilities, communication disorders, fine and gross motor deficits, and physical problems. Parents are encouraged to become involved with the program so they can continue the teaching at home. Babcock County tries to 
offer a more practical "hands on” program to their students. According to the Special Education Director, they concentrate on “things you can’t do in regular school.” While this county does not incorporate community programs, high school honor students volunteer throughout the summer to help with the extended school year program.

Harper County, in central West Virginia, is another site that was contacted. Extended school year services are offered through a home based program only. During the month of July for two and one-half hours in the morning and two and one-half hours in the afternoon, teachers travel to the students' homes and work one-on-one on identified critical skills. Eligibility is determined by regression/recoupment data that have been collected throughout the school year. At the annual IEP review, the team decides which critical skills need to be addressed. Generally, only the lower functioning students were the ones who were eligible for extended school year in Harper County, however, the Special Education Director felt that students with mild learning disabilities would benefit more.

The next county that was contacted is located in the western section of the state. Park County has no set program for extended school year. According to the Special Education Coordinator, they do "whatever meets the child's needs.” Determining factors for eligibility center around regression/recoupment, emerging skills, deteriorating behavior, and students who have a specialized program. Data collected throughout the school year help the IEP team make informed decisions regarding eligibility. Park County has used regular summer school as extended school year programming in the past, however, most programs are individualized and not grouped with any other program. Even though this county director feels that the idea of extended school year is not clearly defined, she reports that her county is “doing it right. I have seen the benefit of extended school year with our county’s kids.” 
Another county that was contacted is Coal County, located in the southern part of West Virginia. They offer extended school year services in a center based setting. The critical skills addressed during extended school year depend on what the IEP team determines from the data collected. All students with special needs are eligible for extended school year in Coal County. Whether or not a child comes to the extended school year program is a decision made mainly by the parents. These decisions are influenced by a variety of situations. For example, previous school year experiences, family activities planned for the summer, or the child needing a break all influence the decision. Coal County tries to make extended school year fun as well as academic. Community programs such as Energy Express have been considered for some students as an extended school year program.

The final county that was contacted is located in the eastern panhandle of the state. Whitewater County does not have a "canned program” for extended school year. It is based on the child's individual needs. If a parent requests extended school year, everything is done to try to honor that request. Services are delivered through home based or center based, and the length of the program depends on the child's area of exceptionality. Eligibility is determined by regression/recoupment of critical skills. For students with behavior problems, socialization is a critical skill. Determining factors for eligibility focus on the appropriateness of the child's behavior within a community setting. In Whitewater County, students with special needs are given top priority for enrollment in Energy Express. According to the Special Education Director, although Energy Express is not written in to the IEP as extended school year, there is a special education teacher on site to provide consultation if necessary (Bonnett, 2002b). Two sites were chosen as research sites based on geographical location and the type of extended school year program described. These two sites are typical of all sites which were initially contacted. 
Table 1

Sample of Extended School Year Programs Offered in West Virginia

County Types of Programming

Babcock

Harper

Park

Coal

Whitewater
Three week program, all day long

Five week program, three times per week, all day long

Home based program during July

Special Education teacher goes to one student's house for two and one-half hours in the morning and another student's house for two and one-half hours in the afternoon

Based on student need, no set program

Center based program

Three days per week for six weeks

Center based program one to two months for one-half day

Home based program

Packets sent home for parents to use with their children 


\section{Instrumentation}

In case study research, it is important that researchers are experienced and adequately trained in the observation/interview process. In this case, my own experiences in education are relevant since my biases may effect how events are interpreted. I have been a special education teacher for 15 years specializing in behavior disorders. I am currently certified in learning disabilities and mental impairment and I have a Masters degree in behavior disorders from West Virginia University.

My professional experience has mainly focused on students with behavior disorders; however, most of the students I work with receive services in at least two different areas. These areas include learning disabilities, moderate mental impairments and speech and language deficits. I have watched first hand what children experience in the school setting. These students struggle to keep up with their peers until they become so frustrated that they give up. I have seen learned helplessness as a major problem for children with special needs. I believe that it is critical to provide the best possible programs for students with disabilities. I believe that this seldom occurs due to lack of funding.

I have been trained as a qualitative researcher through my experiences as an evaluator for Energy Express. I served as a member of the Energy Express state evaluation team from 19982002 under the supervision of Dr. Gretchen Butera. Additionally, I have successfully completed various research and supervision classes at West Virginia University. I also have conducted two extensive pilot studies regarding extended school year programming. During the Energy Express programs, I have observed the children as they interact with members of their groups. I approach this study with the biases that come from working in a project like Energy Express. This program 
encourages socialization among its participants, therefore making it an ideal summer program for children with academic, social and behavior skills deficits. Energy Express develops strong community collaborations through volunteers and businesses. Additionally, college students are utilized as mentors in the program, helping to strengthen local ties through community service projects. Parents are strongly encouraged to participate in Energy Express.

Kathy Brake, who is my sister, assisted in data collection. She also served as a second researcher to validate data summaries and analysis. Kathy received training in qualitative case study methodology from me and from Dr. Gretchen Butera. Kathy has assisted me with several projects in the past. Kathy is a library/media specialist with Randolph County Schools and brings 25 years of experience in schools to this study.

Data were gathered to determine key stakeholders’ perceptions about extended school year services. The following instruments were used:

\section{Observation}

The purpose of observation is to give the researcher first hand knowledge of significant occurrences throughout the study and provide a means to verify reported activities. Ethnographic observations were conducted. This type of observation allows the researcher to watch, listen, and ask questions about relevant aspects of the participants’ lives (Flick, 2002). According to McMillan and Schumacher (1997), the number of observations conducted at each site depends on the logical termination of the event. Therefore, observations were made on different occasions taking into consideration data saturation at each site. Additionally, low inference field notes were taken during the observation (See Appendix B for observational protocol). Detailed descriptions enrich the researchers understanding of the setting and capture the natural flavor of the activities as they occur. 
The researchers recorded field notes during site visitations through continuous observation and casual conversations. An anecdotal journal was kept through the duration of the study. The field journal was used to record any information which related to the purpose of the study and the research questions (Miles and Huberman, 1994). The journal includes summaries of each observation, including descriptions of participants, interactions, activities, and teaching strategies (McMillian \& Schumacher, 1997).

\section{Documentation}

At each case study site, student IEPs were examined to determine critical skills to be addressed in extended school year. In the IEP there was also an extended school year documentation form used to determine regression/recoupment. A critical skills checklist, developed for each student in the extended school year program, was completed daily to ensure compliance with the IEP.

Interview

Interviews are important in order to understand key stakeholder perceptions regarding extended school year services. There are several advantages to conducting interviews. First, nonverbal behavior can be observed during the interview. Additionally, through the use of probes and clarification, the researcher can encourage the interviewees to be as candid as possible with their answers. Finally, in-depth, direct interaction makes interviews adaptable to all types of situations. A cover script (See Appendix C) was used as an introduction to the interview. A prepared set of 12 open-ended questions were developed and administered on site, over the duration of the extended school year program, to administrators, teachers, and service providers (See Appendices D, E and F). The interviews were voluntary and confidential. Every effort was made to ensure that interviewees were at ease with the researchers. Abbreviated notes were taken on the protocol 
sheet as responses were given. Additionally, the interviews were audio recorded so as to assist in writing a more accurate, expanded summary.

Home Visitation

The researcher made initial contacts with parents via telephone in order to establish an appointment for a home visit. The purpose of the home visit was to informally discuss with and observe parental interaction with their child who has disabilities. Additionally, the researcher conducted an interview of the parents so as to understand any perceived problems or issues surrounding extended school year. The interview consisted of seven prepared questions (See Appendix G). The researcher also took field notes on any comments the parents had regarding the extended school year services their child receives. 
Table 2

Observation/Interview Schedule

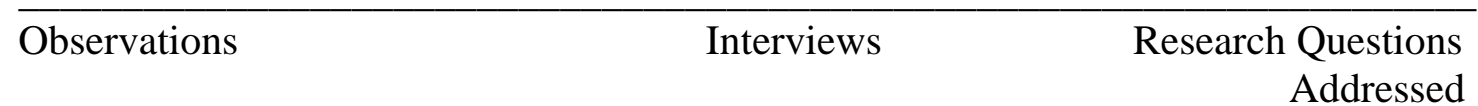

$\begin{array}{lll}\text { Parents } & 3 \times 2 \text { sites }=6 & 1,2 \text { and } 3\end{array}$

Teachers

$1 \times 2$ sites $=2$

1, 2 and 3

Administrators

$1 \times 2$ sites $=2$

1, 2 and 3

Service Providers

$1 \times 2$ sites $=2$

1, 2 and 3

Minimum of 2 hrs x 2 sites x 2 visits per week = 10 hrs per week for 5 weeks 


\section{Data/Cross Case Analysis}

The researcher organized and categorized the collected data according received from parents, teachers, administrators, and service providers. The data reflected the reality of life experiences. Patterns and grouping similarities were priorities in analysis. The information in the field notes was summarized and coded using low inference descriptors (McMillian \& Schumacher, 1997, p. 406). Responses were tallied and summarized, with a special emphasis focusing on the commonalities among observations, interviews, and home visits.

Using the data analysis from each site, the researcher compared and contrasted themes, both within case and across case. In order to establish validity, a second reader also analyzed the data. Data were reduced by examining answers to each question and compiling responses. Next, compilation of responses across readers was then compared. Agreement was sought through discussion in any instances where the readers differed.

The two data collectors conducted short term observations at different sites. Prior to field work, the researchers met and came to agreement on terms and specific target areas. Throughout the course of the programs, researchers met once every two weeks to share emerging themes. A field journal was kept to record decisions made.

Member checking is a means to informally check, through casual conversations with participants, for accuracy and confirmation of research. The researchers rephrased and probed topics in order to obtain more subtle meanings, checking with interviewees to ensure accuracy (McMillan \& Schumacher, 1997). 
Table 3

\section{Data Collection}

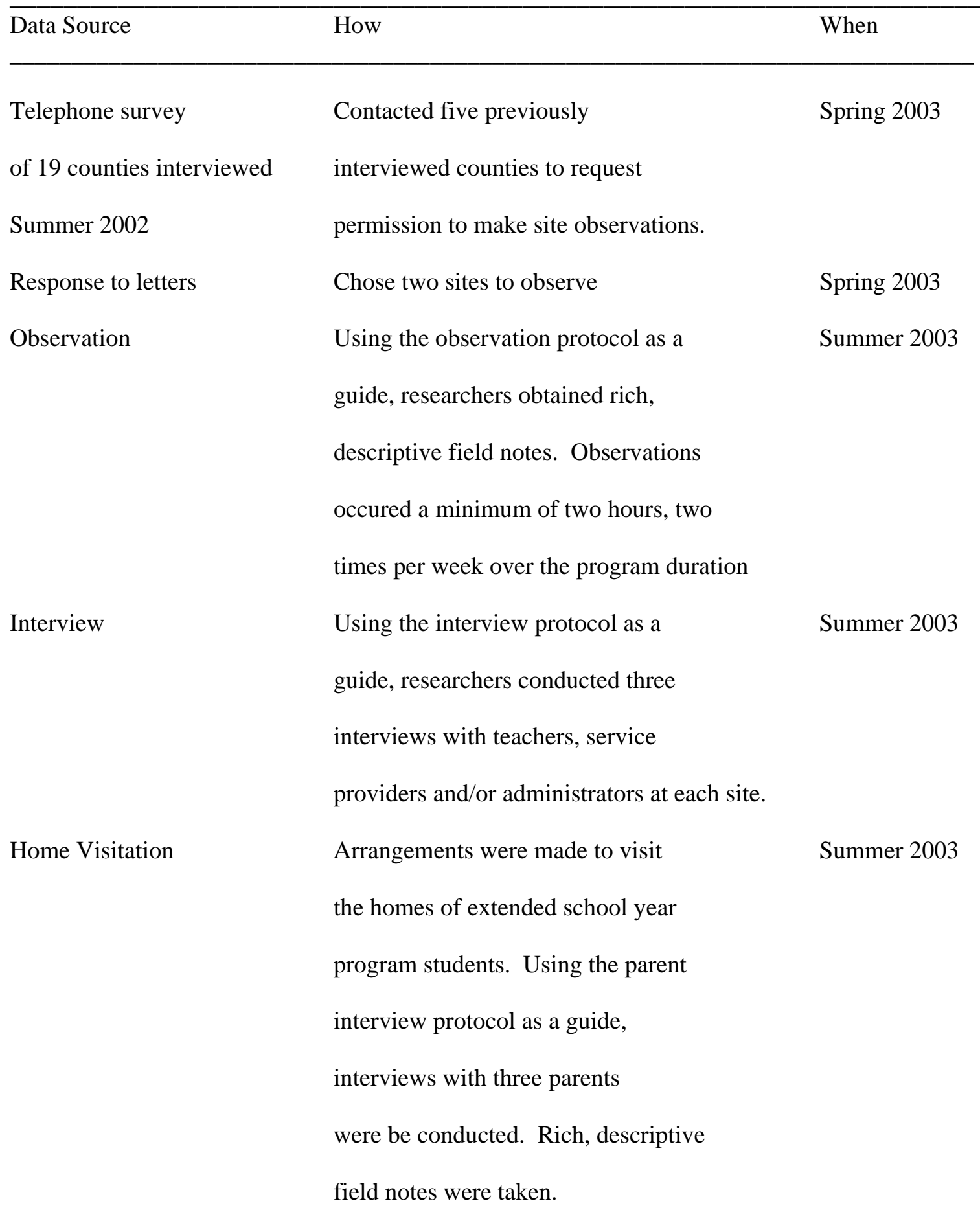


Chapter 4

\section{Coal County}

Coal County, West Virginia is located on the Allegheny Plateau in the southwestern section of the state. It is deep in the heart of the coal mining industry and in fact is the leading producer of coal for West Virginia. There is a statue in front of the county courthouse honoring coal miners and the coal industry.

The county was named for David Coal, the famous hunter and explorer. Although generally known as a son of Kentucky, Coal lived for several years in the part of Virginia which became West Virginia. Coal is known for many heroic deeds including rescuing a five year old girl who had been kidnapped by the Shawnee Indians. When it came time to name the new Virginia County, the son of the now adult woman, in an eloquent speech, recommended naming the county after Coal. The Virginia government agreed and the name became official March 11, 1847.

Many residents of Coal County were allied with the Confederacy during the Civil War. The county was involved in four battles during the war, the most notable being The Battle of the Coal County Courthouse. The Confederacy was sent into retreat during this battle, and the Union took the opportunity to burn down the courthouse in retaliation. The courthouse, located in Marco, was later rebuilt and remains the county seat today.

Coal County has its very own living legend in the form of Bosco Brown, the Dancing Outlaw. Bosco is considered to be one of the last "mountain dancers". This type of dancing is traditionally passed from father to son, and is best recognized as a form of tap dancing or clogging. Bosco's dance floor is an 8 by 4 plywood board or occasionally the roof of his dog Rover's house. Bosco, lives at the end of a hollow in a camping trailer and has a sign posted on his property which 
says “There is nothing in this holler worth dying for. Stay out or be carried out.” Bosco sings Elvis songs and once appeared on The Roseanne Show. There have also been two documentaries produced about his life. Bosco has been quoted as saying such things as "I enjoyed myself, from within myself, on behalf of myself” (Scoggins, 2004).

Coal County boasts 505 square miles with no metropolitan areas. The mountainous region is home to 26, 000 residents with 50 percent being between the age of 19 and 64 . There has been no remarkable change in the population in recent years. The median household income for Coal County residents is lower than the state average at $\$ 26,000$. As a result, 22 percent of all residents are below the poverty level. This is higher than the state average. The population is 98 percent white. The graduation rate is 64 percent (www.wv.gov, 2003).

There are 4,532 preschool-twelfth grade students attending school in the county and of that total, 948 have been identified as having special needs. There are a total of 680 employees in the school district with 126 professional and service personnel devoted to special education.

Extended school year services are provided for 30 to 40 students through a six-week center based program. There is an occupational therapist, a physical therapist, and a county school nurse hired on contract. Additionally, there is one site coordinator, three teachers of students with mental impairments, two teachers for students with learning disabilities, one behavior specialist, one speech therapist, four aides, and four bus drivers for a total of 19 service providers. Bus drivers and aides wear many hats as they help with students throughout the day. On one hand, there is an aide assigned to ride each bus in order to provide any needed assistance while on the other hand, bus drivers assist in classrooms where needed. All the service providers for extended school year are appropriately certified and appeared to be comfortable in their positions. 
The staff is employed for 17 days. The teachers come from 8:00 to 3:00 and the students from 9:00 until 2:00. There are two preparation days for contacting parents, setting up the program, making lessons plans, and organizing field trips. A county employed nurse visits once a week during the program advising and training the teachers. Katrina, the site administrator is responsible for the daily distribution and administration of medicines.

\section{Coal County Talks About Their Extended School Year Program}

\section{Service Providers}

Extended school year service providers in Coal County are selected through a bidding process based on certification and summer seniority. Positions allotted are determined by the total number of students enrolled in the program. One service provider said, “At the time I was selected they were bidding an autism position, and I was the only one certified.” According to the most senior staff member, "This summer will make 15 years. Once in the program you stay in, unless you want out!” Another staff member said, “There is only one preschool special need in Coal County. That teacher decided not to apply, so I got the job.”

The extended school year program utilizes every staff member. When a person accepts a job it is with the understanding that they will be called upon to wear many hats. It is very common to see a bus driver working in the classroom assisting a teacher or the speech therapist feeding a child. "I work as part of a team. Sometimes I work individually with a student; I feed...that's part of my job.

While in the classroom, students are engaged in academic work, socialization, music, painting, coloring, and circle time. According to one of the service providers:

We work on critical skills that have been identified in the IEP. We try to do things you can’t do during the school year. Case in point, Tommy had a problem aggressively 
invading the personal space of others. He loves the pool so when he touched another person, we took him out of the pool for five minutes. He hated that. Within three trips to the pool, he stopped the behaviors and this carried over to the classroom.

Activities for students with learning disabilities, mental impairments, and behavior disorders are delivered together.

In most cases, the extended school year service providers are also the children's teachers during the school year. A team approach is utilized to ensure a seamless curriculum. "Every child in the program is on our caseload. During the school year we meet every Friday to collaborate, and in the process we deal with regression and recoupment." This collaboration carries over into the extended school year program. "Our purpose is truly the extension of the regular school year." The staff is very positive about this aspect of the program. "The classroom things that we do expands the regular school year. I've seen kids really make progress. Students who don't do anything for themselves become more independent.”

Coal County keeps a documentation notebook in a designated area of the cafeteria, and each student's critical skills are listed on forms that were developed by the service providers. (Appendix I, J) “We don’t communicate one on one with teachers outside the program but the form is great. It's a check off sheet that is easy to keep up with.” For teachers who are not part of the extended school year program or who are not teaching their regular grade level in the program, a copy of the documentation checklist is made available to them through the school records. Additionally email, telephone conversations, and monthly meetings are utilized as needed. "It's not integrated, nothing formal. They receive our report of what we have done and if they have any questions, they'll call us.” 
Two days prior to the beginning of the program, the service providers meet and begin planning for the following weeks. During these planning days, the IEPs are copied, thus enabling service providers to incorporate the goals and objectives into the lesson plans. "Since we were monitored (by the state) we copied the entire IEP not just the goals and objectives.” Academics are not addressed as much as behaviors. “That’s where they have problems.” The service providers believe inappropriate behavior contributes to students with special needs being perceived as “different”. The goals and objectives pertain to social behaviors and daily living skills. The focal point of the program implements goals such as following directions, making eye contact, initiating conversation, and developing good personal hygiene.

Parental involvement is an important part of the extended school year program in Coal County. The parents are made aware of the program during the annual IEP review and at that time decisions are made concerning their child's eligibility for extended school year services. Once the program begins, a welcome letter is sent home with a blanket permission slip for field trips. At this time, the bus drivers and parents work out an acceptable pick-up and drop-off schedule. The staff "knows the parents well" and feels comfortable inviting them to observe the program. They are included on trips and are even permitted to ride the bus if they are on the board's list of approved chaperones. Some parents also meet the group at their various activities such as swimming, movies, and picnics.

In our case, we don’t have to involve parents---they already are! Our parents have been spoken to and contacted at least three times. We've trained these parents. We had a student who had an episode yesterday. Within five minutes of his getting here, we were on the phone with his mother. Out parents are very supportive. 
Although it is rare, in cases of severe inappropriate behavior, the parent is asked to come in for a meeting with the staff and the director of the program. Contact with parents comes in the form of phone calls, letters home, and messages through the bus driver, or face to face communications. If children are not attending, a special effort is made to determine the cause and a solution is found. According to the site coordinator, "We focus on the child." Occasionally the staff and parent disagree over services. Every effort is made to accommodate a parent request however, it is clear to this entire program puts the child's individual needs first.

Progress is reported to parents weekly but, according to staff members, progress reporting is still considered to be a weakness of the program. This is mainly because staff is required to send written reports and they believe a phone call is more efficient and personable. At the end of the program a letter, with a copy of the completed documentation checklist is sent to the parents. This checklist is also included in the IEP.

The Coal County staff is very committed to the importance of extended school year. According to Katrina, this is because most of the students "do nothing during the summer. Those kids get breakfast and lunch with lots of socialization. We also pack a 'goody bag' for those we know need it.” Extended school year in this county is a relaxed, fun “camp like” atmosphere. The staff puts forth a lot of effort in making each day educational with varied activities to maintain the interest of the children. As one service provider describes it:

It's important to address the things you feel there will be regression in but it is equally important to address the things you can only work on during the summer----activities that a child cannot experience at home.

Service providers believe their county is doing a good job with the extended school year program. Of course they believe there is always room for improvement and have discussed ways 
to make the program better. Some ideas include starting the program earlier in the summer, increasing the length of the day or maybe even creating three central areas. Increased staff training is also an issue. Overall, they love the program. “From what I've seen---I'm not bragging---they go out of their way. The county spends a fortune. They do an exceptional job.”

Parents

Parents of children in the extended school year first become aware of the program in the child's annual IEP meeting. All the parents interviewed felt they were very much involved in the decision making process for their child. They believed the suggestions and special requests they made were always considered and if at all possible, honored. Parents were comfortable speaking out and felt the committee listened to them.

I go to meetings, and everybody presents. We all decide if it is working, where we are going next. They offer ideas and suggestions and listen to my special requests. I like what they are doing.

One grandmother/caretaker said she attends the meetings because the mother is hard of hearing and can’t understand everything. She said, “They’ve never refused me that I know of. In every way I have freedom to say what I think and they listen to me.”

During the IEP meeting decisions are made as to which students will receive extended school year services, but some parents did not have a clear understanding as to how their child qualified. One mother explained it was because her child missed about three weeks of school due to chicken pox and because of his reading. Another parent said, "He was enrolled in special classes last school year. I'm almost sure that makes him eligible for extended school year. I guess it’s because of his level...he's low.” One parent admitted to not being sure how her son was eligible. She said, "I think they were concerned that if he didn’t come, he might fall back.” 
Parents were also confused about how progress was reported. This is probably due to the fact reports do not look like the information they receive during the school year. Parents appear to equate progress reports to report cards. Parents indicated they were receiving "paperwork" regularly but, as one parent put it, “They (extended school year service providers) never told me about his progress. I am just going by the paperwork he brings home.” Another parent said, “I'm thinking I'll get a progress note. She sends home newsletters to tell us what he's done, places he goes, memos telling us it was a good trip or just a personal note.” Yet another parent responded, “No progress. Now that I haven’t gotten but if I called I'm sure they would tell me. Everybody has been nice.” Parents indicated that if they had a question or concern they felt free to contact any one involved with extended school year. They all reported going through the proper channels---talking to the teacher first and then going to the director if they felt it was necessary.

Parents were aware of the many important aspects of extended school year and knew why it was relevant for their child. What the parents felt was important, was directly in line with the individual needs of their particular child. In the words of one parent,

I think that it is important to keep the school routine. For my son, its small things---getting up, getting dressed, and catching the school bus, eating breakfast. He actually likes this routine better. For him, it's fun to be involved. For me, it's consistency.

Another parent said,

He's at different levels for different tasks. There are so many things he needs that whatever they do with him is good. His weight is down. They make sure he eats and they watch his diet. They work on his fine motor skills.

Most parents indicated that reading was an integral part of extended school year. "They help him with his reading. The most important thing for him is to learn how to read.” Other parents 
believed reading to be essential but also added that spelling and math was necessary. One parent felt they should work on the things they do at regular school, but added "They take him places which have helped him be around others.”

Not all parents were completely happy with all aspects of the program. One parent expressed concern with the rotation of staff during the program because she felt it was disruptive to the routine of her child who is autistic. "I didn't like that he just got used to one and then they're gone. Routine is important to him.” Another parent felt the extended school year program should be longer.

Overall they were very positive about how extended school year in Coal County was addressing the needs of their children.

I think it's a good thing. He's really benefiting. He has made friends. I've seen changes in him...things that he’s learned, things that he does that I didn’t teach him...he comes home and he does them.

The parent of a teenage boy responded, He's at that age on a teenage level and doesn't want to be with his parents. They go places plus they do work. It is good for him to do what they do. Every experience is a good one. Parents were also happy that their children were able to get out in the community and get involved. They felt the field trips helped their child learn how to get along better with others. One young mother responded, "I like them going out into the community. With two other little ones, I can't take him by myself.” Most parents felt their children worked hard all during the school year and deserved time to do fun things without the pressures of a classroom atmosphere. In the words of one parent, “I think it’s good. At least he’s not sitting around here doing nothing and forgetting what he does know.” 


\section{Teachers From The Coal County School District}

The teachers interviewed were employed by the county school system as special education teachers but were not involved with extended school year. These teachers understood the eligibility requirements for the extended school year program and were aware that summer regression and recoupment within the first nine weeks of school plays a large part in a student's eligibility. Regression/recoupment is measured by the previous school year and during the first week of the current school year they check to see if the children are able to accomplish their goals. The special education teacher conducts testing to determine regression/recoupment. Critical skills are then selected and documentation is collected throughout the year to be presented at the annual IEP meeting. For reading a standardized fluency test is used while math testing is left up to each individual teacher.

It depends on the goal. I check for frequency and accuracy. I'm getting better at it. What we've found in the past is some of our objectives were not measurable.

Although parents, other teachers, and administrators also attend the meeting, the special education teachers interviewed felt they were best suited to determine eligibility and played a large part in the extended school year section of the IEP.

These same teachers expressed concern as to the amount of time spent on socialization as opposed to academics. There was a general lack of knowledge concerning what occurred in extended school year programming and what information they did have was based on hearsay. One teacher said “I don’t think this county is addressing what is important. I've been told they do no academics. It's mainly field trips and socialization.” Teachers felt that providing a continuum of instruction consistent with the regular curriculum should be the most important part of the 
extended school year program. “It hasn’t really been academic. I usually end up tutoring kids throughout the summer.” remarked another teacher.

Teachers were also concerned with how the extended school year is integrated with the regular school year programming. They stated they were not aware of where the follow up information was located. “There's no follow up. I get nothing. Does any county?” Another teacher remarked, “The only follow up I get is 'Jerry really liked swimming.” Yet another teacher said, "What's follow up? I don’t know unless it was put into the main file at the board office.” Teachers felt that Coal County’s was geared for the student with severe handicaps. They believed that students with learning disabilities were not included and were usually overlooked.

It was believed that extended school year was for socialization purposes only. While they felt socialization was important, they were more concerned that the child's individual critical skills were not being addressed. “I honestly can’t tell you. I have no clue. When you don’t actually work it, you don’t know. One teacher laughingly remarked, “Give them food. They will come.”

\section{Administrator}

As with all extended school year programs, Coal County is provided federal funding to support the services the children receive. Coal County does not integrate any community based programs with extended school year. Maureen, the Coal County Special Education Director, indicated she was not sure of the legalities of doing so. Katrina, the extended school year coordinator, briefly discussed the history of the extended school year program.

Fifteen years ago, it was done as a home based program. When we became centralized, we had one bus driver, one teacher, one Speech Therapist, and we did our own cooking. As years went by, we were able to hire a janitor and a cook. This year we have a staff of three MI teachers, one BD specialist, 
one LD teacher, an occupational therapist, and a physical therapist on contact, two Speech Therapists, a nurse, four bus drivers who also serve as aides, and four aides who ride the bus and also help with the kids. We're so staffed, it's pleasant.

In an interview Maureen was very positive about the extended school year program offered in her county. She believes the services offered give students the opportunity to make practical application to what they have learned during the school year. In praising the staff on their accomplishments, she states “I think they're wonderful. They work on other things besides academics. For example, they practice social skills for students with behavior disorders. Maureen feels that providing an exemplary extended school year program is an expensive undertaking but is well worth the money spent.

In the interviews, Maureen and Katrina agreed their county was doing a good job providing extended school year programming. They felt they were meeting each child's individual needs. Maureen said she would like to get the children involved who do not attend. She also indicated she knew the parents would prefer to have the program every day, all summer.

\section{Diary of an Extended School Year Program}

July 15, 2003

The first day at the Coal County site was not only busy; it was also a pleasant introduction to the extended school year program. Upon arrival, teachers and staff began discussing the events planned for the day. There was a lot of enthusiasm which spilled over to the students when they began arriving. Katrina, the site administrator said,

With extended school year, you never know from one day to the next how many you will have. Attendance is sporadic and we always have to be ready with alternate plans. 
Each student was individually greeted by their teacher as they entered the cafeteria where a hearty breakfast of biscuits and gravy was being served. The cafeteria itself was bright and airy, lending to the pleasant, cheerful, and relaxed atmosphere.

As the children ate, the adults came together to take care of housekeeping issues. Bus lists were checked, permission slips recorded, attendance was taken, medicines were administered, and plans were being finalized for the activities of the day. The goals and objectives checklist was also updated at this time (Appendix H). All of this information was kept in a notebook which was placed on a centrally located table in the cafeteria. This table was designated as "the teacher's table.”

On this particular day, the staff was dealing with a bus not picking up children and various student related health issues. Additionally, because of the bus issue, there were parents delivering students to the program. The teachers took this as an opportunity to make contact with parents and discuss student programs.

When breakfast was finished, the students whose critical skills were focused on self-help assisted in clearing and cleaning the tables. The students were instructed how to wash the tables and in some instances the children were given hand over hand instruction. The children also washed the sides of the tables and chairs. Wringing out the washcloths was as an area of instruction. One staff member was overheard saying, "Now when you go home you can help your Mom wipe off the table.” There was a lot of verbal praise and smiles as everyone prepared for the day. It should be noted that interaction between children was limited; however there was continuous interaction between adults and students. Once the cafeteria was clean the children then went to a classroom used for exercise. Students, teachers, and aides participated in the "Walk 
Away the Pounds” aerobic exercise program. This was a very popular activity as several individuals dropped by to join in the fun.

Students whose IEP critical skills were academically oriented went to individual classrooms for math and reading. English was also part of their curriculum. During this time, these students focused on ability appropriate activities in a traditional classroom setting. On this particular day, a group of students was completing math worksheets. These students were being assisted by their teacher and an aide. Another class of students was finishing a reading project. In both classroom situations the students were seated at desks and raised their hands for help. During the same time frame, the preschool aged children who attended the program concentrated on developmental skills. These included fine motor skills, gross motors skills, socialization, and selfhelp.

After these morning activities were completed, all of the students were reassembled in the cafeteria. The focus then turned to socialization or "getting what they need... 'critical skills'... in real-life situations.” Students were divided into groups for various activities.

One group went to the outdoor Farmer's Market which was located by the State Capital in Charleston, West Virginia, a short bus trip. There was one adult for each child on this trip as several of the students were autistic. During the trip, the teachers and aides engaged the students in conversation by discussing what they were going to do. However, there was little child to child interaction even though some of the children were sitting together.

The adults also discussed who would help each child at the market, who could get along with each other and the strategies they would employ with each student. Students brought store lists and money from home. One child's mother had written a note requesting only "half-runner” green beans. 
At the market, each child was given a basket to carry. If difficulty in walking or balance was an issue, they were given a grocery cart to push instead. The students walked through each section of the market, and the adults helped them choose the best vegetables. It should be noted that the "half-runner" green beans looked especially good that day! The students filled their grocery bags and also were responsible for paying the cashier. At the end of the activity, the participants were rewarded with a small snack at the indoor, air-conditioned restaurant.

The trip home mirrored the trip to the market. Teachers and aides discussed the successes and failures of the trip. They also talked to the children about their experiences. Overall, it was an extremely pleasant learning experience for everyone involved.

Katrina's group of teachers, aides, and students took a short field trip to the local Kroger’s and Big Lots. During the trip through town she pointed out, to the students various landmarks in the town. She showed them the courthouse and, at the firehouse she talked to them about "why this building is important.” Each experience became a teachable moment for the students.

The first stop was at Big Lots. Before the students got off the bus, Katrina told them what she was looking for by holding up a picture clipped from a Big Lots circular for everyone to see. She said, "See who can find this first." The person who found the item was allowed to pay the cashier. As the students got off the bus Katrina reminded the student to look both ways before crossing the street.

Once inside the store one student had the honor of getting the cart as the teacher walked toward the section of the store where the item can be located. All of the students walked closely behind. Katrina named things on the shelf and at one point held up a strainer and said, "What do we use this for?” The students who knew answered enthusiastically. In the pasta aisle, the students took turns naming various pastas. There was canned lunch meat in one aisle and she 
asked the students “What kind of sandwich does your father take in his lunch?” One student pointed to the type of meat his dad likes.

Upon reaching the aisle where the laminator they were looking for was located, Alyssa, a student, found it and was allowed to take it to the register for payment. The students then returned to the bus.

Katrina was very patient with the students as they wandered through the aisles. It was clear they had been in the store before and were well known to the clerks. The store employees talked to them and the students responded. Everyone worked together to ensure a pleasant experience and that the students were comfortable in their surroundings.

The next stop was Kroger’s. At this grocery store, they were looking for ice cream. The students had to decide what flavor and Neapolitan won! Everyone was happy! There was constant casual conversation with the students. Boyd, another student was talking to Katrina about a trip he had taken the night before with his poppa. He was allowed to sit in the front seat of the vehicle. Later, Katrina laughingly remarked,

Boyd's poppa doesn’t like me because I won’t let him sit in the front seat of my vehicle. 'He wants to,’ poppa says and I want to weigh 150 pounds, but it ain’t gonna happen! The visit to Kroger’s was handled in the same manner as Big Lots. The students were naming things in the store, pointing out items they liked to eat, and they were searching for the items they were going to purchase. Another student, Timmy, worked on shopping without buying anything. This was to help teach him proper shopping etiquette. "We also teach how to buy appropriate items. There's cat food in his home, and they don't own a cat. He can't buy cat food with me.” 
It was then time to return to school for lunch. The students reassembled in the cafeteria to enjoy lunch (Except for the students on the Farmer's Market trip who ate lunch later in the day). Lunch is handled much like breakfast. Students got their tray at the window and were permitted to sit where they chose. For the most part, the students sat with the staff. Conversation and interaction was encouraged.

Katrina’s son, who is Alyssa's peer mentor during the school year, visited for lunch. During this time he also used a teachable moment by encouraging Alyssa to taste the chocolate pudding and prompting her to use her napkin to wipe her face. He also encouraged conversation, asking her to tell where she attended high school. This is Alyssa's last year but plans were being made to allow her to come back to school next year as a helper.

After lunch, all of the students in the building went to view Yesterday’s Tomorrows: Past Visions of the American Future which was part of the Smithsonian Institution Traveling Exhibits. This exhibit was housed in the Bituminous Coal Heritage Foundation Museum. The students took a tour and saw various items from the past and ideas for future inventions. They also participated in a coal mining tour.

The day ended on this happy note. The children were returned to the bus and upon arriving back at school, preparations began for going home. After the students left, the teachers stayed another hour to reflect on the events of the day. This was also a time of planning for the next day's events and activities.

July 16, 2003

The morning routine did not vary. The breakfast room was again full of students and teachers interacting. One particular situation was very poignant. Nancy, the Speech Therapist, 
was feeding Robert, a student with severe physical handicaps. As she fed him, she asked him questions about his morning. “Did you have spaghetti for breakfast?” Robert shook his head no and Nancy prompted him to say "No” and he complied. When asked “Did you have sausage?” Robert said "Yes” without a prompt. Another student walked by and Nancy encouraged socialization between the two boys. She said, "Say hi to Robert." and the boy replied, "Hi, Robert.” Robert smiled and Nancy said, “He’s talking to you. You can touch him.” She then helped the boys shake hands and said, "You've made a new friend.” This was not an isolated incident. This type of interaction was encouraged each day and students were very responsive. The children were prompted to verbalize and socialize using various teaching strategies such as hand over hand, physical guidance, and verbal prompting.

On this day, there was an added air of excitement! The afternoon included a trip to Charleston to go the movies! A Charleston area cinema offered free movies on Tuesday during the summer, and the Coal County extended school year program took this as an opportunity to address proper public social behavior. Prior to boarding the two buses, it was necessary to take care of routine details such as giving medicines and changing diapers. It was then time to board the buses. Students with physical handicaps were loaded first. Then, the rest of the students were very carefully secured in their seats with seatbelts. Once everyone was settled, a total of 25 children and 12 adults settled in for the 30 minute trip to the theater.

The trip to Charleston was filled with conversation. Teachers were asking students questions about the scenery, and this generally led to other conversations. The teachers concentrated on getting students to engage in conversations with each other also. Before they got off the bus, teachers reminded students of the rules and the expected, appropriate behaviors for a public setting. "Do we move from seat to seat during the show?; Do we yell at our friends?; Is it 
ok to laugh out loud?” The students were well versed in the appropriate responses. Even though going to the theater is part of their normal extended school year program, it is interesting to note that as the students got off the bus they were in awe of their surroundings and very animated. They were also very excited about the rocking chair seats in the theater.

The days feature, “Like Mike”, was a story centering on a little boy who wishes to play basketball like Michael Jordan, an appropriate movie because it emphasized being able to overcome adversity. The staff sat with the students and from time to time quietly answered questions or made clarifying comments. Throughout the movie, the students were well-behaved and afterward expressed their appreciation for this special treat.

On the way home, the teachers again took the opportunity to discuss the movie and encouraged the students to overcome whatever problems they might encounter.

Once back at the school, the students ate a late lunch and went home. July 17, 2003

Saint Thomas State Park - This trip was a lesson in local history. The students, teachers, and all other support staff boarded the buses to visit Saint Thomas State Park. This is a once a year event, and all the students are included.

The morning began with an incident that involved a child who is deaf and his interpreter. Jason refused to get on the bus for the trip. Katrina did a quick assessment to determine if there was a physical problem which could be causing his reluctance. Once it was determined that he was not sick or in any pain, the teachers concluded the problem was behavioral in nature. This young man had a record of similar outbursts, and his behavioral plan was put in place. His interpreter repeatedly signed for him to board the bus. Jason continued to refuse and eventually his 
interpreter, who is also his sister, picked him up and carried him to his seat. She placed him beside of the window and sat down next to him in order to keep him from standing up.

Katrina later confided that his sister was in a difficult position. She is his interpreter during the school year and during extended school year because she is the only teacher qualified for this position. Since she still lives at home, she is in constant contact with him and sometimes feels frustrated. She and Jason have been unable to make the difficult adjustment from school to home and vice versa. On this particular day, there were several incidences of conflict and, as a last resort; Jason was taken to the bus to wait while the others finished the tour.

The first stop was the wildlife refuge. Students were able to walk through the park and observe the animals in their natural habitat. Teachers were using this time to reinforce appropriate public behavior, using good manners, and following directions. Additionally, the students and teachers were discussing the various animals and how they live. There was a great deal of interaction between students while visiting the refuge. While this is a yearly trip, the kids all showed excitement at being there. Overall, it was a very enjoyable and educational experience for all!

At the park, there was a traveling train and coal exhibit which the park manager opened especially for the students. Since the exhibit consisted of fragile, intricate parts, each adult was assigned one or two children to watch. The exhibit consisted of miniature coal towns with an extensive train track intertwined. The students (and adults) were totally enthralled. The students learned about the various communities and the importance of trains to the coal mining industry. Every adult took the opportunity to explain the exhibit to their assigned child/children and also made any behavioral corrections necessary. There was a lot of positive conversation and again, the 
experience was not only educational, it was very enjoyable. In speaking with the staff, Katrina said, "Just thought you'd like to know that deep down you can make a difference."

It is important to note that every one of the adults was given the same role. Everyone was expected to teach and maintain control of the various students. There was an abundance of teamwork and everyone appeared to be very willing to help in any situation. This was a seasoned staff and it showed!

July 24, 2003

After breakfast, the students followed their normal routine by going to classrooms to complete academic activities in compliance with their IEP's. In one classroom there were six boys and two teachers. The students were working on reading comprehension activities, math sheets, and alphabetical order. As the students worked individually, the teachers walked around the room asking students if they needed help and making sure the students understood the assignment. The teacher was also checking papers and making corrections as necessary.

In another classroom, a teacher was reading orally to students. She then had the students read silently as she went to individual students and had them read aloud to her.

The students were on task and appeared to be interested in what they were reading. Other classes in the building included aerobics, speech, preschool, occupational therapy, and physical therapy. In each situation the students were participating and no behavior problems were observed. The academic environment was non threatening and very effective.

In the afternoon, everybody went to Riverpark, a nearby swimming park complete with waterslides, olympic size pool, and a lazy river. The students swim every Wednesday afternoon. At the pool, a few of the parents met their children. Teachers were assigned students for whom to be responsible. The teachers participated in the swimming activities. Students were encouraged to 
socialize with other individuals at the pool, and this was obviously an ongoing situation since people recognized them and responded to them.

While at the pool, Katrina talked about the extended school year program and confided that the Wednesday swimming trips were somewhat controversial. To people not involved in the program, trips like this seem to be "playtime” and a waste of county funding. Katrina pointed out the various functional learning activities happening such as learning to follow safety rules, recognizing safety signs, identifying objects in the environment, and increased vocalization. She then said with a smile, "Every morning people you know get together and plan ways to make your life more difficult.” July 29, 2003

The morning started out as usual. The staff met before the children arrived and planned the day's activities. Upon arrival, each child was greeted and had breakfast before going to their various classrooms for instruction. Afternoon plans included fishing and a trip to Charleston with the highlight being a walk down the brick road of Capital Street.

The Capital Street area had been newly developed with numerous quaint shops and restaurants. The street was lined with trees and flowers. There were park benches for those who just want to sit and enjoy the day!

The first stop was a book store. Students were allowed to browse on their own. In one section of the store an employee was reading aloud, and many of the students joined in this activity. Further down the street, there was a candy and nuts shop. This was a very small store so the students had to go in by groups while the others sat outside and waited their turn. If the students had money they were allowed to buy and Katrina was observed "floating loans" to those who did not have money. Everyone had a treat when they left the store. 
The next stop was the Daniel Boone Hotel which boasts a glass elevator. Most of the children were eager to take a ride but some had to be encouraged to get on the elevator. The view of Charleston from the top floor was spectacular. The children enjoyed the ride so much that they all wanted to do it again!

As the group walked down the street, the students were encouraged to point out various things they found interesting. At the end of the first block, one staff member gave a short lesson on crossing the street safely. She showed them how to use the button to change the light and pointed out the "WALK" and "DON'T WALK" signs. For those who were unable to read, she explained the symbols. When they reached the next blocks, the lesson was reinforced through student participation.This journey ended at the Farmer's Market where the students rested and had refreshments. The students and staff then boarded the bus for the return trip to school.

As the groups reassembled in the cafeteria to go home, the students who had been fishing were especially excited and had a story to tell. During the day's fishing trip, one of the bus drivers had been bitten by a large catfish as he was attempting to remove it from a student’s hook. Needless to say, he dropped the fish, and it became the one that got away! July 30, 2003

The morning routine started as usual but there was an incident on the bus involving a young girl who was deaf. She did not attend the program on a regular basis and had difficulty being away from her parents. On the way to the program, she was hitting and kicking other students. When the bus arrived at school, the aide promptly brought the child to the teacher. The teacher dealt with the incident by explaining to the girl what she did wrong and why she shouldn't behave in that manner. However, the situation escalated when another student approached the girl. 
While his intentions were to help, he made the situation worse. She finally settled down when the teacher threatened to call her father. She was fine for the rest of the day.

An important aspect emphasized during breakfast was using good manners. On this day, the students were required to sit at the table until everyone around them had finished eating. The preschoolers had a particularly hard time staying seated, and staff members strategically sat behind students to keep them from getting up.

After a morning of academics, an impromptu trip to the Dairy Queen was a refreshing treat in the afternoon. The Dairy Queen was located in downtown Castleburg, and even though it was a short bus trip, getting the children settled on the bus was a huge undertaking. Children in wheelchairs were loaded and strapped in. The other students were familiar with the routine and when they boarded the bus, they began buckling their seatbelts. However, some of the children still required assistance. Upon arrival at the Dairy Queen, Jason did not want to get off the bus. The bus driver persuaded him to leave the bus with him. Once inside Jason refused to sit with his sister and instead stayed with the driver. At the Dairy Queen, everyone was permitted to get a treat of their choosing, and each child did their own ordering. Katrina paid for the treats out of extended school year funds. 
July 31, 2003

There was a feeling of anticipation and trepidation as the program came to a close. During the morning discussion time, the staff expressed concern for the children since many of them depended on the meals they received during the extended school year program. There was also concern, because school would not begin for another month, that students would regress.

However, once the children began arriving none of these worries were evident to the children and the day proceeded as usual.

One group of students listened to, watched, and signed songs. One song they particularly enjoyed was “My Mother’s Snoring” which included verses about cows, pigs, geese and horses kept awake all night by snoring! There was one little guy in the front who was having trouble listening and participating appropriately. The staff chose to first ignore the behavior. When that didn't work, one of the teachers intervened and had the boy come back and sit with her. She did this very quietly and this took care of the problem without a scene.

The older students were enjoying a time of awards. Awards which were given included super star, good listener, good conduct, and safety. Every child received participation ribbons and certificates. Children were also given take home books. These were given according to reading ability. Then, it was the children's turn to give presents to staff members. For example, Nancy received a bird feeder, and John got a fishing mug full of gummy worms.

The final afternoon was spent at a picnic at a local park. While it was difficult for staff to end the extended school year program, they were all aware that the new school year was just around the corner! Everyone was upbeat and seemed to be looking forward to September! 


\section{Putting It All Together}

Since its implementation, Coal County’s extended school year program has grown and flourished. There is a sense of camaraderie among key stakeholders. While they readily admit there is always room for improvement, an overall satisfaction of the success of the program is evident.

The program in Coal County clearly exhibits the essential components for successful extended school year programming. It is child centered, has family and community involvement as well as commitment on the part of the school system.

The program concentrates on the child and is tailored to meet the student's individual needs. This is evidenced through the daily documentation in which progress toward the student's goals is recorded. The students are exposed to new and various opportunities in non-classroom settings while teachers observe their interactions in order to help them obtain a greater awareness of how to help the children become the best they can be.

Respect and trust go hand in hand as parents and service providers work together. The family is important to the success of the extended school year program. Based on the data collected, parents are comfortable with the service providers, and communication is open; however, parents expressed concern with the manner in which progress was reported to them. Parents are encouraged to become involved through actual participation in socialization activities. When new skills are exhibited at home, parents are quick to acknowledge the progress their children have made. They are advocates for their children. They feel their voice is important and that they are heard. 
The community is involved and committed to the Coal County extended school year program. The service providers feel very comfortable taking the students into the community and the children are made to feel welcome as they participate in day to day activities such as going to the grocery store or park. The level of functioning of the students appears to improve with each visit. Community members are familiar with the program and in many cases mentor the children in the learning process. However, there is little integration with other summer programs.

The extended school year program would not be possible without school commitment. The school district not only funds the program, it encourages follow through with regular school and the sharing of goals. The district also provides information to the parents and regularly offers support to families. There is a clear understanding of the importance of the school district's involvement. Coal County’s special education director is very supportive of the extended school year program and is quick to point out the camaraderie of the staff and the success of their program In Coal County, extended school year is a way to let students with special needs experience life. They are taught socially appropriate behaviors in real life situations. The students see and do things which are new opportunities for them. "Some of these kids would not even get to go to Charleston if not for the program.” One service provider summed it up when she said, "We aren't going to cure them but we can make them better.” 


\section{Park County}

Park County, West Virginia is located at the mouth of the Kanawha River where it empties into the Ohio River. The largest town, Springfield, is also the county seat. Park County is known for the "Battle of Springfield" which occurred in the early 1770's. Chief Cornstalk of the Shawnee Indian Nation was a man of peace, but felt he must follow the desires of his people, who voted for war because of the continued encroachment of settlers into territory claimed by several Indian Nations. Both sides of this battle incurred heavy losses and eventually, Cornstalk convinced his tribe to discuss a peaceful settlement.

After their defeat, and return home, a council was convened to determine upon what was next to be done. The stern old chief rising, said, "What shall we do now? The Long-Knives are coming upon us by two routes. Shall we turn out and fight them?" No response being made, he continued, "Shall we kill all our squaws and children, and then fight until we are all killed ourselves?" Still the congregated warriors were silent, and after a moment’s hesitation, Cornstalk struck his tomahawk into the war post, with compressed lips and flashing eye, gazed around the assembled group then with great emphasis spoke, "Since you are not inclined to fight, I will go and make peace” (www.wv.gov, 2003, p.2).

Unfortunately, Cornstalk was later murdered by men who were bent upon revenge. Legend has it that Cornstalk placed a curse upon Springfield and that curse still wreaks havoc today. The tragic fall of the Bronze Bridge has been attributed to the curse of Cornstalk. Additionally, the Birdman legend is said to be the physical manifestation of the curse. According to eyewitness accounts, the Birdman, with his glowing red eyes, stands seven feet tall and has a wingspan of ten feet. The creature has never hurt anyone but his mystery lingers today. 
Park County is a mostly rural county which is 432 square miles in size and is located between Parkersburg and Huntington. The terrain of the area is level over bottom land within the foothills of the Allegheny Mountains rising above the river plain. Natural resources of the area include deposits of salt brine, clay, gravel, sand, coal, natural gas, timber, oil, and pulpwood (www.wv.gov, 2003, p. 1).

The largest employment is in the retail trade, with health services following closely. Often, employment is found in other counties. There is also employment in neighboring county's industrial and agricultural trades (www.wv.gov, 2003).

The population is 26,000 and there have been no major changes over the past several years. Fifty-six percent of the people are between the ages of 19 and 64. Ninety-eight percent are white. The median income is $\$ 27,000$ which is lower than the state average. Twenty percent of the population lives below the poverty level, and this also is higher than the state average. Seventy-two percent of the people of Park County are high school graduates. There are 4, 267 students who attend Park County schools. The school system employs 599 teachers and service personnel.

Park County employs nine extended school year service providers to instruct 22 students who have been identified as eligible for the program, out of a total of $745 \mathrm{~K}-12$ students who are receiving special education services. The service providers act independently and are responsible for working with the parents of their students to schedule meeting times and places.

Each service provider is also responsible for developing day to day routines including lesson plans, meals and breaks.

Extended school year in this county was originally scheduled to be conducted in the same place and at the same time as the county's regular six week summer school session. However, 
since there were not enough students enrolled in summer school, it was cancelled, and an alternative plan was made for extended school year.

In the past, extended school year was a home based program with teachers traveling to each student's home. During the summer of the study, the program was located in several areas throughout the county, including a modular classroom behind the middle school and a corner table at the local public library. Students were transported to and from the location by their parents. A summer lunch program was available at the local high school; however, students did not participate on a regular basis.

\section{Park County Talks About Their Extended School Year Program}

\section{Service Providers}

Service providers indicated the jobs are usually posted, applications are completed and positions are then filled. This year the county had a difficult time filling the positions due to a lack of applicants. In fact, the service providers who did work were personally contacted and asked to work the extended school year program. The service providers were under the impression they were asked because they were familiar with the students involved in the program. “This year I was contacted to do it since I had worked with the student in the past. He was one of my students, and it was requested that I work with him.” All of the service providers, with the exception of one, were certified in all areas of special education. This provider, who was the only one to call the county office requesting a position, had a Bachelor's degree in athletic training and a Master's in health.

According to the service providers, extended school year is offered to students on an individual “as needed” basis. Individual Educational Programs (IEPs) are developed during the regular school year. Critical skills are identified at that time and data are collected regarding a 
student's progress. For example an identified critical skill might be following one-step directions without prompts. Throughout the school year, the student will be observed and notations made about the student's progress. This data helps determine a child's eligibility for extended school year. According to one service provider, We offer extended school year from 9:30 to 12:30, four days per week. I get the room ready; I call parents and set up times. I look at critical skills. They are different from school. It's pretty much the same routine as in the school year. I get the students to generate some of what they want to do.

Communication about the student occurs in several ways. In some cases, the special education teacher who teaches the child during the school year, contacts the service provider via phone, written or face to face communication. In one case, the service provider taught next to the teacher and student. Therefore, she was familiar with the situation and was knowledgeable about the student during the school year. In yet another case, the service provider explained, "I had him in extended school year before, so I knew pretty much all I needed to know.”

A copy of the child's IEP was available at the board office. All service providers reported having a hard copy of the goals and objectives was crucial. "Yes, it's the first thing I get. The main goals are established, and the critical skills are identified.” Another service provider reported that having the goals did not necessarily mean you understood how to proceed. She explained:

Our Special Education Director gave me a list of kids, and then she gave me the goals I was to work on. I wasn't involved in any of the students' IEP's. I think it is better to have your own students. 
Parents are involved throughout the program, according to the service providers. They help make decisions concerning meeting times and days. They provide transportation. According to one service provider, “We discuss progress, school to home and home to school generalization techniques.”

Progress is reported to parents verbally on an almost daily basis. According to a service provider, "I keep charts, and the parent gets a copy. We also give them a copy of the IEP goal sheet with progress indicated.” This written progress occurs at the end of the program and is placed in the special education file of the student.

According to service providers, student goals and objectives are followed from their IEP. “We'll do an update on the IEP so it can be placed on record.” Follow-up includes verbal discussion with the school year teacher providing him/her a copy of the progress notes. "Followup is easier when the service provider is also a part of the regular school year.”

The service providers believe Park County is meeting the basic extended school year needs. “They are doing much better than they were. Not excellent, but good. The pay was not competitive, and teachers were hard to find.” The system is now paying $\$ 5.00$ more an hour. "From what I can see, to me, everything has run pretty smoothly.”

Service providers believe one way to improve would be to expand the extended school year program to include all children with special needs. "It could be like a day camp. Any one who wants to could sign up and come for any amount of time during the day. We've talked about it and bounced ideas amongst ourselves.”

Service providers also believe the program needs to be given more thought and consideration. In the opinion of one service provider, "The criteria (for attendance) are all wrong, 
but that is the state, not the county. Actually, with the criteria now, none of these kids would qualify.”

Parents

The parents interviewed feel they are central figures who take an active role as a member of the IEP committee. Most feel their ideas are considered, and the IEP committee is very receptive to them. The main goal of a parent is to make sure their child gets the services they need. As one parent puts it, I don't ask for so much that it is impossible to get. I don't want to be unreasonable. There may be a bigger battle to fight down the road. I bring ideas of things I would like to see happen, and they listen. They have always tried, within the constraints of what they are working with. Another parent had the same goal, but for a different reason. As she explained, "I want to make sure he gets the services he needs. I distrust the school system from bad experiences in the past." She explained that she felt the administration looked upon her as "troublemaker" because she has been an outspoken advocate for her son. She said,

I don’t think I ask too much. I think they want to save money, and saving money is more important to them than giving what the child needs. I've had things to be agreed on in IEP meetings, and the pages were exchanged on the way to the copier. When I got home, it was different from what I signed.

Overall the parents understood how their child qualified for extended school year. "My child is the same as every other child. Critical skills, as determined by the IEP, have not been met and cannot be maintained throughout the summer without some form of intervention.” Parents used their child's disability to explain why they need extended school year. As one mother 
reasoned, "She needs interaction. When she takes a break or is not on schedule, she begins to exhibit inappropriate behaviors.”

Each parent interviewed believed the extended school year program was designed to meet the needs of their child. According to one parent, who expressed concern over her child entering middle school,

The county went out of their way to get the co-teacher he is familiar with since he doesn't do well with changes. I feel they are doing all they can to make the transition to a new teacher better.

Another parent stated, “The extended school year teacher is the teacher my child has during the year. They are keeping it as much the same as they can.” One parent felt the extended school year program is giving her child more than she gets during the regular school year. This is basically the result of increased "one-on-one” instruction. "She is actually talking now. She signs and says sign words at the same time.”

The parents reported they learned about their child's progress mostly in the form of oral reports. Additionally, some service providers gave the parents written progress reports at mid-term and again at the end of the program. These reports highlighted the activities of the student but are sometimes problematic according to parents.

Usually after a session we go over things they worked on and things I can do at home. Sometimes she says 'We worked on this.' or 'He did well on this.' But generally I don’t know exactly what they do. It's a very frustrating thing because my child doesn't talk, doesn't write. I'm getting no sense of what he's learning or how he is doing on the goals. First and foremost, each parent reported if they had problems they talk to the teacher in charge. Some parents said it actually depended on the problem. For example, 
I would probably talk to Donna (the service provider) first, and then call the director if the problem cannot be resolved. The director is extremely nice and her son goes to the same babysitter...the joys of a small town!

Parents believed it was important that the extended school year program address the critical skills. Structure and routine was also an area of importance for parents. They felt their children did much better if they stayed in a structured program throughout the summer. One parent said that if her child was not motivated through a summer program, she would simply "sit in front of a TV and watch a movie.” Additionally, she and other parents believed inappropriate behaviors tend to escalate if their children are not actively involved during the day. The extended school year program helped students retain their skills. "She needs to have some place to get up and go. She’s very regimented, and when she doesn't have a schedule, her skills and speech suffer.”

Most of the parents were not completely satisfied with the extended school year program offered by Park County. They felt there was a set program and a set way of doing things but that it revolved around the convenience of the county, not the students. One parent said, "We are certainly appreciative they are offering something. It has helped a lot, and it's great.” However, parents had a sense of frustration as to the inadequacy of the programming. They cite such needs as transportation and socialization. The parents wanted their children to have their usual teachers. Students with disabilities have trouble warming up to someone they are not used to, and by the time they become familiar with the service provider, the summer is over.

If it were a perfect world, extended school year would be the same as she's used to...the same structure, the same time frame, one-on-one but also have interaction with other children in the building. 
Parents generally agreed that the problems relate to funding. They ascertained the county was just not willing to put enough money in the program to hire enough personnel to handle the needs of the students. The disagreement was usually over salary, since what the county is willing to pay is not what the service providers want, a parent explained.

I don't think I ask too much. They (the board of education) want to save money. Saving money is more important to them than giving what the child needs. What they do is good, but there is a lot more they could do.

This parent also felt the school system does not look to her child's future. She voiced concern over the fact that the county was relying too much on Medicaid services. “There is a lifetime cap. I didn’t want what they (the school system) are required by law to give him, billed to Medicaid.”

One parent was especially dissatisfied with the speech therapy offered. Pointing to a student across the room who is being supervised by his speech therapist as he shredded paper, she said, “There’s your speech therapy...he’s not getting speech.”

\section{Teachers From The Park County School District}

The teachers interviewed were employed by the county school system as special education teachers during the school year, but were not involved with extended school year. They felt that one of the most important aspects of extended school year is the motivation needed for children to attend. They believed there must be activities which ensure skills are maintained, thus preventing regression over the summer months.

Teachers described criteria for extended school year, reporting that whether or not a student is able to retain information learned from one school year to another as important to decision making. Critical skills are marked on the IEP of the student. However, these teachers are not always clear as to how data is collected or how students are tested on these skills. 
Those students who do not retain identified critical skills based on their IEP qualify for extended school year services, according to the teachers. However, these teachers agreed that usually the students with the most severe handicaps are the only ones placed in the program. “Our county sends out an application to the parents.” As reported by the teachers, other ways students qualify include special parent request and school district decisions.

All teachers agreed that an IEP committee made the final decision about a students’ eligibility. The IEP committee consists of a special education teacher, a regular education teacher, parents, student (if age appropriate), an administrator, guidance counselor, and any outside agencies that may be involved with the student. In some instances, the diagnostician who conducts and analyzes evaluations pertaining to the student was also in attendance.

According to the teachers interviewed, regular education teachers were not involved with data collection unless the student attends a general education class. Data was collected by compiling student work samples related to the critical skills that have been identified on the IEP. After six weeks, work samples were again collected and compared.

Teachers interviewed were confused as to how the IEP goals and objectives are addressed during extended school year. Some of them indicated they were not involved with any of the students who qualified and others said they did not attend the IEP meetings. However, they did not feel that extended school year programs were connected to the school year activities.

“I do not feel that extended school year is integrated with regular school,” reported one teacher. Special education teachers felt they were sometimes "left in the dark" as far as extended school year is concerned. Another teacher commented, "I did not receive anything from the extended school year teacher. I found a brief narrative in the students' file that listed the books 
they used.” Teachers believed the students receiving extended school year services were benefiting from them, but they also felt that many needy students were not in attendance.

I'm sure it probably keeps them in their routine, but I think there are many students who should receive extended school year that are not being identified as eligible for services. The teachers did not know who attended extended school year and felt the county board of education does not do a good job of "getting the word out.” As one teacher put it,

I don't think they want to offer extended school year to a lot of students. They don’t want to spend money on it...and another thing, I don’t think parents understand that it is available.

\section{Administrators}

According to the Park County Federal Program Director who also serves as the special education director, extended school year is funded from federal program money using IDEA LEA applications. Services are determined by the students’ IEP. According to the Federal Program Director, “Whatever meets the individual needs of the child. There are no 'set' programs.” Park County offers extended school year in a variety of settings. Administrators report that students receive services in their homes, in schools, at the public library as well as in different community locations such as stores and restaurants.

Service providers were selected by administrators according to the students’ disabilities. They were paired with students based on teacher certification, location, and familiarity with the student. "We serve students pretty much on a one to one basis.” All of Park County’s extended school year service providers were appropriately certified in special education with the exception of one who is was on a permit issued by the West Virginia Department of Education. According to the special education director, 
We try to have the students' regular special education teacher provide the extended school year services if possible, but, if that isn't possible, the teacher who normally works with the student during the school year sends the service provider a narrative about the student, along with current IEP goals and objectives.

If the student normally works with specific materials, the extended school year service provider uses the same materials so as to develop a consistent program across settings, according to the special education director.

After service providers receive the list of students they will be serving, it is up to them to contact the parents and set up an initial meeting to discuss extended school year programming, she reported. The administrator was not sure about follow up with the students’ regular school program. "This is my first year in this position (special education director), and I'm not really sure what type of follow up has been established.” Ideally, students who participate in extended school year programming make a smooth transition between the regular school year and extended school year, she thought.

Park County’s special education administrator pointed out that while the guidelines surrounding the extended school year program are “vague, ambiguous, and not clearly defined”, her county does a fairly good job of keeping extended school year an individualized program. "I like how we are doing it. I have seen the benefit of extended school year with our county kids.” 


\section{Extended School Year At A Glance}

July 7, 2003

The first extended school year service provider observed was Sherry, who provided extended school year services for three elementary students she also teaches during the school year. She met with them individually at the Park County Public Library three to four hours weekly during the month of July. The library offered a quiet, air conditioned atmosphere where, while there were many people around, distractions were at a minimum. Sherry (who was eight and onehalf months pregnant!) appeared to be a calm, quiet person with a ready smile.

On this day, she and her student sat at a corner table in front of double French patio doors that led to the outdoors. As they worked, Sherry engaged her student in quiet conversation and the student appeared to be quite at ease asking questions. Teaching materials included worksheets, real money, and puzzles. These were used to grasp the concept of counting money. Sherry maintained an excellent rapport, keeping her student on task and interested in the activities. However, she also recognized when her student needed a break and allowed time for her to read.

Another service provider, Donna, had two students with autism in her extended school year program, Nathan, a 12 year old middle school student, attended in the morning, and Cassandra, a 13 year old intermediate school student, attended in the afternoon. Both participated in extended school year four days each week for five weeks. In the morning session there was a classroom aide, Jeri, to help with Nathan but Donna conducted the afternoon sessions with Cassandra alone.

Donna's classroom was located in an unattached building next to Springfield Middle

School. During the regular school year, this building is used in part as a special education classroom. The room was air conditioned with a refrigerator, microwave, and television; however, 
its appearance made it less than an ideal setting. There had been no attempt to make the room a pleasant place to learn. Boxes were stacked throughout the room, and there were no bulletin boards or other visuals to make the room more attractive.

On this particular afternoon, Cassandra entered the classroom somewhat reluctantly. In her hands she held a small plastic doll which she was twirling. The session began with music and singing. Donna sang several children's songs and encouraged Cassandra to join her. While Cassandra did not sing, she smiled and clapped her hands, making it obvious she was enjoying the activity. Next Donna directed Cassandra to the calendar and weather chart. Cassandra was familiar with the routine, and when asked pointed questions such as "Is the weather today hot or cold?” and "Is it cloudy or sunny?” she vocalized "hot” and "sunny.” Both answers were correct responses. Despite Donna’s attempt to encourage her, Cassandra was not interested in the calendar and did not respond when asked what day it was. Instead, Cassandra went to her seat and began to cry. Donna ignored the behavior, and during a break explained that Cassandra often indulges in “fake” crying in order to get her way. Donna’s attempt to redirect Cassandra was finally successful and she was able to continue with the lessons.

The next session consisted of safety and survival card recognition. In this activity, Cassandra was shown cards with safety hazards on them. These cards included poison labels, walk/don’t walk signs, and stop signs. Whenever possible, Donna used “real life” items such as a real EXIT sign or poison labels on bottles for generalization. She would ask Cassandra questions such as "What should you do, or what could hurt you in this picture?" As soon as she asked the questions, Donna would answer them herself, and Cassandra just watched.

There were also picture cards to match. Cassandra had to match pictures which helped her recognize everyday items such as door, window, shoe, and different colors. She was prompted to 
sort and categorize the picture cards. Cassandra was unable to perform this task alone however she was receptive to Donna physically guiding her hands in order to help her sort. During this activity, Cassandra constantly twirled a penny or the small doll with her hands and tried to get out of doing her work by “fake” crying. Throughout the session, Cassandra complained of being tired and constantly tried to put her head down. At one point she indicated that her back was hurting, and while Donna was extremely patient, she finally gave in and let her lay down. While Cassandra was lying down, Donna read to her and asked her questions about the story. There was some interaction going on with Cassandra and her teacher, however she was easily distracted, and her language skills were limited to two or three word phrases such as “Barbie,” “back hurts,” and “I’m tired.”

July 8, 2003

This morning began with breakfast, after which, Ernie, another student with autism, joined Nathan for the first session of the day. Ernie’s teacher Joyce and Donna’s classroom aide also joined the session. Ernie entered the room smiling and went from person to person shaking hands. He was very friendly and tried to interact with Nathan by shaking his hand. However, Nathan was not responsive and actually moved away from Ernie. The boys sat across the room from each other, and one had an adult sitting beside of them.

Session one began with a language lesson which consisted of children’s songs and counting to music. Everyone but Nathan joined in by clapping their hands. Nathan continued to distance himself from the others and began pacing around the room. Upon noticing this, Donna changed the activity to a walking/galloping exercise, hoping Nathan would join in. Although there was very little participation by either student, Donna said, “This is our favorite time of day! I just know that one day he'll (Nathan) start singing with us!” 
Next, the students were directed to the daily picture schedule of the work for the day. Donna methodically reviewed each picture explaining to the boys what activities were in store for the day. She also showed them the weather chart and followed the same routine she had with Cassandra the previous day. With assistance, Ernie chose the correct weather card and placed it in the appropriate slot on the chart. Nathan watched.

At the conclusion of the first session, a five minute break was given. According to Donna, Nathan is permitted to “do things he likes during break time.” He usually played with a string or an ace bandage, flicking it in the air while making a low guttural whistling sound. At this point Ernie went back to his room, and Nathan spent the remainder of the morning with Donna and Jeri.

Donna, who was trained at the University of North Carolina in Chapel Hill, NC, uses the “TEACH” method with both of her students. This method is designed for use with students who are autistic, although Donna reported using it with students with other disabilities. According to Donna, TEACH promotes “normalizing” experiences for autistic students. Teachers are trained how to provide the students with an opportunity for choice. It emphasizes understanding the problems of autism and advocates for individualization of services delivered. A consistent morning routine is established with four work sessions conducted at a quick pace so as to eliminate behavioral distractions. After each session the student is allowed a five minute break.

Midway through the session Nathan heard his mother's voice and became aware that she was in the next room. His acting out behaviors began to escalate, and he showed he was agitated by pacing, rocking, and making low guttural noises. At one point he tried to pull his pants down. Donna explained this was his sign for needing to go to the restroom and promptly took him there. On the way to the restroom, he saw his mother and went to her. She had to help get him into the restroom. Afterward he went back to class. He had to be redirected several times and was never 
able to resume the lesson. Also during this time, Ernie, who was in the classroom next door, kept opening the door to see what was happening. He also came into the classroom and began shaking hands with everyone and blowing kisses. He tried to shake hands with Nathan but Nathan ignored him and walked away.

July 9, 2003

At the middle school, Donna was preparing for her morning session with Nathan. All four sessions of the program began with Donna sitting across from Nathan and Jeri sitting beside him. There were three color coded TEACH boxes on Nathan's left (one for each session). Each box contained work for him to complete by sorting and categorizing. The first box had laminated pictures with matching cards. On a sheet there were pictures of various items. There was also a set of cards with the same pictures. Nathan was to place a picture from the cards on the correct picture on the sheet. Nathan picked a card, and Donna guided his hand to the correct picture.. Clapping and praise followed. They continued until each card was in its proper place. When the work was completed, it was moved to Nathan’s right, which signified the work was finished, and session one was completed.

During another session, Donna placed two cards in front of Nathan and asked, "Where is the boy?” or "Where is the girl?” and then guided Nathan’s hand to the appropriate card. While she was doing this, Donna kept up a dialogue describing the pictures prompting Nathan to focus on the task at hand.

The final session had pocket folders and laminated pictures to categorize various shapes, objects and people. Nathan was required to look at the picture card and place it in the pocket of the proper category. The same routine was followed as in previous sessions with Donna guiding Nathan to the correct area. 
An independent work area was set up in the classroom. This area included several activities which the students could complete. These activities included sorting silverware, folding wash clothes and play dough. When Donna attempted to direct Nathan to the centers, he became very agitated. He was rocking back and forth, looking around the room and pacing. Several times he approached the observer, getting very close as he flicked his ace bandage at her. Donna tried to ignore the situation, hesitating to intervene until Nathan lunged at the observer and knocked off her glasses. At this point, Nathan had to be physically returned to his chair and even after Donna attempted to redirect him, Nathan again approached the observer, repeating his behavior. July 14, 2003

At the library, Sherry's session with her student was a continuation of lessons regarding the concept of counting money. They were once again seated by the French doors which led to the outside. On this day, two small children were running around in the work area but they were quickly removed by their parent. During this time, Sherry kept her student on task, and helped her handle the distraction. The student was once again using real money as she and Sherry pretended to make transactions in the way it would be at a store. This particular student appeared to be very comfortable working in a one on one situation, but once again tired and requested a break. During this time, Sherry sat at the table and allowed the student to quietly explore the library. The student soon gravitated toward a group of elderly women who were part of the grandparent program at the library. Although they are not part of the extended school year program, they readily welcomed Sherry's student into their reading circle. After a short time, Sherry called her back to continue with the lesson.

In a conversation with the ladies, it was discovered that during the school year they all volunteered in special education classrooms and were familiar with extended school year 
programming. They were very complimentary and felt it was a good program. "I don’t know what the ones that can’t get along in a regular classroom would do without it. They’re just too slow to keep up and need help during the summer.”

Meanwhile at the middle school, Penny who is a speech therapist and Joyce were working with Ernie. The classroom was next to Donna's and was similar to it, with boxes piled everywhere. Class was being held in the kitchen area of the room. Joyce and Penny also used the TEACH method.

After thoroughly washing the table and reminding Ernie not to touch his nose, they began putting together “Bob Evans bags.” During the regular school year Ernie’s school had contacted the manager of the local Bob Evans Restaurant. They worked out an agreement which allowed the students with disabilities to put together the bags the restaurant gives out to children. "It's a freebie for them, they're glad to let us do it.” In exchange, the students get to visit the restaurant for a free lunch once or twice a year. Penny was excited because she was allowed to continue this during extended school year.

Penny held a clear plastic gallon size bag. Ernie picked up a coloring book, two crayons (green and orange) and put them in the bag. He then handed the bag to Joyce, who put it on the table and held it so Ernie could close the bag with tape. Penny talked to him constantly, encouraging him to stay on task and praised him for working. Ernie was somewhat uncooperative, not wanting to complete the task. He attempted to touch his nose, but Penny held his arms. When she let go, Ernie immediately tried to touch his nose again. It had become a game with Ernie; however, Penny was consistent and kept him working. July 21, 2003 
Donna and Jeri appeared to have a good working relationship. They were focused on the student and each session was a team effort. Today, Nathan began the session very agitated and much time was spent redirecting and keeping him focused on the task at hand. However he was generally unresponsive and/or pulled away from the teachers. Both teachers were persistent with Nathan, encouraging him to complete his sessions. There was constant praise, clapping, and plenty of smiles to go around.

Nathan's behavior escalated throughout the morning, and he exhibited increased instances of inappropriate behavior which were dealt with quickly and firmly. Donna and Jeri were careful to keep Nathan away from the exits since he was trying to get to the doors, and he had gotten out of the room on a previous occasion. Nathan also went through the desk drawers and threw paper.

There was a countywide lunch program Nathan sometimes participated in, however since Nathan became easily upset around noise and crowds, Donna usually prepared a lunch in the classroom with Nathan's help. On this day, since Nathan was already agitated, Donna chose to fix a lunch consisting of macaroni and cheese and corndogs. Donna, Jeri and Nathan sat down together to eat. They carried on a conversation, trying to involve Nathan, who was completely unresponsive.

Because his behavior was so erratic, Donna broke from the usual routine and decided to read a story to Nathan. As she read, he constantly roamed around the room, flicking an ace bandage in the air and whistling in a low, guttural voice.

During the last hour Donna unexpectedly had to leave. Jeri completed the day’s sessions with Nathan. When she tried to get Nathan to go to his seat, he became aggressive and pushed her away. At that point Jeri let him continue to roam the room; however, she shadowed him. Penny, 
who was in the next room came over to offer assistance and ended up staying until the end of the day.

July 22, 2003

It took Ernie eight minutes to get out of the car today. There had been a change of his routine and he had a different caregiver. While the caretaker sat in the front seat observing, Penny and Joyce took turns trying to coax Ernie out of the car. In his own time, Ernie finally got out of the car and went into his classroom.

Penny spent part of the day teaching sequencing to Ernie using story sequencing cards. She showed Ernie three pictures. Using an augmentation board, he responded by pushing the correct button when asked, “What happened first?” Ernie had a difficult time knowing which button to push so Penny covered the wrong buttons with a sheet of paper and then guided him, hand over hand, to the correct button. He smiled and clapped his hands!

There was also a poster board mounted with individual pictures of Ernie and his classmates. The pictures had been cut and framed in different shapes (oval, diamond, circle and square). Penny asked Ernie, “Where is Nathan?” or “Where is the circle?” He responded by pointing to the correct picture.

The last activity was “Lotto.” Ernie matched pictures of every day items with picture cards. This session with Ernie lasted 60 minutes without a break except for the transition from one activity to another. Throughout the session Penny verbally praised Ernie and clapped her hands. “Good job!” made him smile. She also recorded Ernie’s accomplishments and/or any problems that occurred during work time. Later, during planning time, Penny and Joyce met and discussed what could be done to make the sessions better. They each felt they had difficulty ignoring his inappropriate behaviors and expressed concern that he would deliberately do the opposite of what 
was asked of him. For example, when Penny was working with Ernie with the sequencing cards he kept rearranging the pictures. Penny would make eye contact and tell him "No" while guiding his hands to his lap. Immediately Ernie would repeat the behavior, and it eventually became a game for him. This continued for five minutes until Penny finally put the cards away and redirected Ernie to another activity.

When Ernie’s caretaker came to pick him up, he was ready to stop work and go home. He showed the caretaker his work, and once again left when he was ready. After Ernie left, Penny reported that the work Ernie does in his sessions is the same work he does during the regular school year. Ernie receives assistance from the Autism Center in Huntington, West Virginia. A representative from the Autism Center had called and informed them a behavior specialist would be conducting observations on Ernie in his extended school year class. She also said that Ernie’s mother had called with concerns about inappropriate behaviors Ernie was exhibiting. These behaviors included hitting, spitting, pinching, and pulling hair. Neither Penny nor Joyce knew the Center had been contacted and were visibly upset because Ernie's mother had not informed them anyone would be visiting from the center.

Observations with Sherry have been concluded. She was required to go on bed rest due to pregnancy complications (Sherry gave birth to a bouncing baby girl on July 24, 2003). July 23, 2003

Park County also offers speech and sign language instruction during extended school year. The county hired a certified sign language instructor and also contracted with Linguacare, an agency located in Huntington, West Virginia, to deliver speech and language services.

The classroom designated for speech services was located at the middle school in a separate building behind the school. It was a big, bright room; however, it had also been packed 
up for the summer. The bulletin boards were bare, nothing was hanging on the walls, and desks and boxes were piled around the room. Instruction took place in front of the room with the teacher and the student sitting face to face in student chairs. Speech instruction was 30 minutes in length, with most students receiving 10 sessions. Students came at different times throughout the day. Parents were permitted to remain in the room during instruction; however on several occasions this became a problem because the student would focus more on what was happening in the room than on the lesson. It was even more distracting when parents brought siblings.

On this day, Sara, a seven year old student with a hearing impairment, arrived with her mother, little sister, and an interpreter. The interpreter signed to the student as the speech teacher introduced words. It was later reported that the interpreter visits the home and attends school with her.

During the session, activities were kept at a quick pace to keep Sara focused and on task, while strategies such as “You be the teacher”, and “Let me know if I'm doing it right” helped hold Sara's interest. During this activity, the teacher made sounds, and the student corrected her when she was wrong. Another strategy involved the teacher rolling a chip down her shoulder, and as she was doing this she would say "Car going down the hill.” Sara would then imitate the behavior and attempt to repeat the sentence.

The teacher also used picture cards to help Sara identify correct sounds. The teacher held up two cards and would say a word which matched one of the cards. Sara would point to the correct card and say yes or no if the teacher had pronounced the word correctly. There was plenty of verbal praise, clapping and smiles throughout the session. As Sara left the classroom, her speech teacher gave her a homework folder for practice at home. 
Next door, Donna was working alone with Nathan. On the table were games, puzzles, and books. There was also a video of the movie "Toy Story” playing on the television. Donna brought her grandson with her today. He was sitting at Donna’s desk watching the movie. Nathan was having another rough day as he continued to roam around the classroom in an agitated state. Donna's continued redirection was ineffective. As soon as she took Nathan to his seat, he jumped back up and began pacing again. Additionally, Nathan rocked and made noises.

When it was lunch time, Donna turned the tape off and prompted Nathan to put away the games, books, and puzzles. He picked up a book and began carrying it around the room. Donna cleaned off the table and then took Nathan to wash his hands. Donna again prepared lunch and they sat down to eat.

After lunch Donna read the story "The Kissing Hand” to Nathan and her grandson. As she read, Nathan rocked back and forth in his seat. Donna would ask Nathan questions about the story but he was unresponsive. Through all of this, Donna optimistically remarked, "I know he has all of this knowledge just waiting to come out.” 


\section{Putting It All Together}

There are many facets to the extended school year program in Park County. A true sense of caring and belief in the idea of extended school year exists; however, key stakeholders have expressed concern as to the effectiveness of the program. Some essential components of successful summer programs, are not readily visible.

The program is child centered since almost everything is designed to meet each student's individual needs through one-on-one instruction. While each student is afforded the undivided attention of his/her teacher throughout the session, it is not to the best interest of the child since there is no relationship with other students, teachers, or adults. Thus, the programming is limited to the classroom with no opportunity for interaction with others.

The parents of the Park County students have mixed opinions as to the effectiveness of the extended school year program. According to the data, there are parents who are very frustrated because they feel disconnected from the program. As one parent stated, "I have never felt the extended school year services were that good.” According to these parents, it is very difficult when a child has limited communication skills.

On the other hand, the data suggests there are parents who believe the extended school program is successful. These parents expressed gratitude that a program was designed to help their children maintain skills. The parents in Park County are also advocates for their children. When it comes to trying to get the best possible services, they have strong voices and are comfortable expressing the needs of their children. In the words of a parent who believes her child benefits greatly from the program, "God has smiled on us in many ways. He has sent people to help us.” 
There is very little evidence of community involvement in the Park County extended school year program. The exception to this is the Bob Evan's program, which is also utilized during the school year. However, there is no evidence of collaboration between community members and service providers. The people of the community were not utilized as mentors, guest readers, or volunteers. There was a perfect opportunity for the students to participate in the countywide lunch program but the teachers chose to eat in the classrooms because of inappropriate behavior exhibited by their students.

School commitment is in evidence since the program is funded through the school district. However, the commitment is basically limited to funding. There is little evidence that the school district encourages extended school year for its students and planning for it is not extensive. Extended school year services are discussed at the annual IEP meeting, and parents are informed about the program but the school system also requires an application be completed before a child will be considered for extended school year. This is a major drawback as parents appear to be intimidated by this process. Additionally, according to the data, it is practically impossible for the school district to find teachers who are willing to commit to the program.

In Park County, extended school year is basically "regular school” that is held during the summer. Activities are confined to the classroom with no opportunity for community experiences. While consistency and routine are an important aspect of regression/recoupment for children with disabilities, this type of extended school year program greatly reduces the socialization aspect. As Karweit, (1985), points out, unless the additional time spent in extended school year is accompanied by changes in teaching strategy and curricula, the additional time might simply lead to fatigued students. 


\section{Chapter 5}

As stated in Chapter Three, the purpose of this study is to describe the perceptions of key stakeholders about how extended school year in West Virginia meets the needs of students with disabilities who qualify for the program. This chapter presents the cross-case analysis of the study. Three research questions were addressed:

1. What are the beliefs of key stakeholders (parents, teachers, administrators and service providers) about extended school year? How do these perceptions compare/contrast with one another?

2. How do the practices of extended school year programs relate to the essential components of a successful summer program for children with special needs?

3. What is the relationship between the beliefs of key stakeholders and the practices implemented during extended school year programming?

In July, 2003, on-site observations and interviews were conducted to examine two extended school year programs of West Virginia. Service providers employed for the summer were interviewed, and parents were selected to be interviewed through a random sampling. Additionally, several county employed teachers were interviewed.

The responses to the interview questions were summarized by taking into account the positions held by each stakeholder and the similarities and differences in their answers. Additionally, observations and field notes were recorded and summarized. The data was then examined in order to identify common themes.

Overall, the school districts are satisfied with the way the extended school year programming is being delivered. However, key stakeholders in both counties believe that lack of 
funding is a major barrier to providing adequate extended school year programming. They do not believe that lack of funds is the cause of all the problems within extended school year. They believe their county is doing the best they can with the monies they have, but improvements could be made in many areas.

As discussed in the literature review, the essential components of child centeredness, family and community involvement, and school commitment must be adequately met in order for extended school year programs to be successful. Throughout the study, the necessity for each of these components to be in place became apparent. "Some school districts have become very comfortable and familiar with ESY services and routinely include it in timely IEP discussions...still others are simply uninformed” (Kraft, 1999, p.1). The following data show the more experienced Coal County program meets some of the essential components, while Park County, has a less developed extended school year program, and is struggling to find its place. Cross Case Analysis

Child Centered. In Coal County all of the IEP meetings are held at the end of the year. Eligibility for extended school year is determined based on documentation from the child's special education teacher and decisions are made by the entire IEP team. The teacher determines what data are collected. Baseline data are taken in the spring. In the fall, at the end of the first nine weeks, data are again taken. In order to determine regression/recoupment, results are measured by comparing the data collected in the spring of the previous school year with the new data. If a student shows significant regression and struggles to regain previously learned material, then they will be eligible for services the following summer. According to one service provider:

When a kid qualifies, they do so because they have a moderate to severe deficit in academics, socialization, communication, daily living skills, and/or self-help skills. We 
run the whole gambit. Services are delivered to everyone from teacher's children to welfare kids. We specialize in unique problems.

Extended school year services begin in June for those students who are recommended for extended school year services. The gap in time between when eligibility is determined and services are delivered is no doubt problematic in some cases. Although the data gathered indicates that a student has "regressed", a full nine months between this decision and the extended school year services suggest that in many cases, students who may require services are missed.

Park County identifies critical skills at an annual IEP meeting held during the school year. Critical skills are recognized as skills that cannot be recouped within a nine weeks period. Data are collected in the form of work samples that are maintained from one year to another and presented at the meeting. Other data include an application which is sent to the parents. The completed applications are used to help determine a child's eligibility for the extended school year programming. The application process is very cumbersome which discourages parents from enrolling their children. According to one Park County service provider, very few students are eligible for services. "Only the most severe students qualify. It's usually something the parents request. Actually, with the criteria now, none of these kids (referring to the currently enrolled students) would qualify.”

Park County parents feel the decision for eligibility is basically a decision of the administrators, not the teachers. However, they do feel the school district has tried to be accommodating within the constraints of their budget. "I have always tried to negotiate more than we get. They know. I ask for the moon and try to be reasonable knowing I am not going to get it.” Both school districts are well versed in the federal and state guidelines pertaining to the question of eligibility for extended school year. Identified critical skills are based on the amount 
of time a student takes to recoup skills after a break in their educational process. Both districts measure recoupment within a nine-week period of time. While the IEP process of determining eligibility is similar in both school districts, the outcomes are vastly different.

According to service providers, Coal County relies heavily on the data collected by the teacher when determining the eligibility of a student. Conversely, Park County service providers indicate that while data collection is used to help determine eligibility, an application, which is filled out by the parents, also plays an important role and has the effect of reducing the numbers of students in extended school year.

In Coal County children of varying degrees of disability qualify for the program, and services are delivered to students who exhibit deficits not only in academics but also in communication, socialization, daily living, and self-help skills. On the other hand, Park County’s critical skills focus on academic deficits. Communication services such as speech and hearing are offered, however, there is little evidence of socialization or self-help daily living skills. Children in the Park County extended school year program are isolated as opposed to the center based program offered by Coal County. Additionally, service providers indicated their county only serves the students with the most severe physical and mental disabilities.

Coal County offers extended school year services three days per week for five weeks. Teachers report at 8:00 A.M. for planning, and sessions for students begin with breakfast at 9:00 A.M. The student's day ends at 2:30 P.M. while teachers stay for another half an hour in order to discus any problems or concerns that may have occurred during the day as well as get material ready for the next day. 
The service providers in Coal County are proud of their relaxed camp like setting. Socialization is encouraged between younger and older students during breakfast, lunch, and field trips. However, students are grouped by age during instruction.

All Coal County teachers interviewed agreed that one of the most important aspects of extended school year is the time spent out of the classroom. In contrast to Park County, working with smaller numbers in the summertime helps them to help the students maintain critical skills which include socialization and life skills. Teamwork is also key to the success of the program as teachers work together to utilize different strategies in their classroom. Some of these strategies include hand over hand, verbal prompting and physical prompting.

The daily routine of the Coal County extended school year program includes feeding, diapering, and administering medications. The Coal County program employs a cook to provide breakfast and lunch on site. Classroom activities help to address academic skills such as reading and math, while socialization, communication, daily living skills, and self-help skills are addressed through afternoon activities. Field trips are an important part of this county's extended school year program. On any given day, the group may travel to the park, the courthouse or even to the movies. They also go bowling and swimming as well as visit museums, the farmer's market, and local grocery stores. Each experience is viewed a teachable moment as critical skills are applied to these real-life situations.

On the contrary, Park County has no set program for delivery of services. It is a seven week program with varying meeting times that have been agreed upon by parents and the individual service providers Services are offered in per hour sessions or in some cases per day sessions. All sessions end by July 31st. Teacher-student ratios are generally one to one, in some instances two to one but never any larger than one to three. Classes are held in locations 
throughout the county. In one case, the service provider meets children at the local library. All speech and hearing impaired services are delivered one to one.

Meals in Park County extended school year are combined with a free countywide summer lunch program for which all students are eligible. However, during the study, none of the service providers regularly took advantage of the program. According to Donna, “The lunch program is too overwhelming for my student. There are different kids every day, and he doesn’t know anyone there." Several factors contributed to this including a feeling of intimidation on the part of the students, student behavior, and time constraints. Consequently, there is little opportunity to address socialization or connect with the community in Park County.

Several specific instructional strategies were observed over the course of the Park County program. Emphasis was placed on hand over hand instruction and behavioral principles. Students were rewarded for good work. Other strategies included praise, verbal prompting, and physical prompting.

Some parents with students in the Park County extended school year program expressed dissatisfaction with the way progress is reported. In the words of one parent,

I see some folders, the programs and I realize how difficult it is when he doesn't have a way to express himself. I don’t feel like I know what he is doing. I need something concrete. Other parents get a number on a sheet. I don't get anything.

Coal County’s extended school year program encompasses many areas of a student’s development. While the continuance of academics is emphasized, it is not the "heart and soul" of the program. Much importance is placed on the socialization, communication, and self-help aspects. Key stakeholders embrace this emphasis and believe these features are just as important as academics. 
Socialization is stressed heavily in the Coal County program. "That's what we're all about. We address and deal with problems the children face in real-life situations.” The mornings of the extended school year program are devoted to academics but every afternoon is a time when socialization skills are practiced. The basic rules of socialization are taught to each student. They are always encouraged to initiate conversation with their peers. They are also taught to respond appropriately when someone is speaking to or interacting with them. These skills include making eye contact, smiling, and listening. During this time, students are also taught about personal space and physical contact. The teaching of socialization skills is not restricted to the classroom setting. Students have an opportunity to practice appropriate social skills during trips to grocery stores, museums, parks, theaters, water parks, and even the farmer's market. While engaging in these activities, the students are coached and prompted to practice appropriate responses in given situations.

Even though there are socialization goals in the IEPs of students within the Park County program, these skills have not been designated as critical. Because of , services are restricted and socialization is mostly limited to teacher/student interaction. In one case, two students, who are non-verbal, were occasionally brought together for morning activities. However, there was no interaction observed between the two, nor was any activity especially designed to elicit peer interaction.

Several parents interviewed were dissatisfied with the lack of socialization in the Park County program. "Kids with special needs need socialization. They need to be around other students.” stated one parent. Another parent responded by saying

This is the first time anyone has been in the room. Usually, it's two to one (teachers to student) with no other children. He needs to interact with children his own age. The IEP 
talks about peers, but there are no peers to work with. They are not doing anything with his critical skill of socialization.

Coal County offers numerous field trips so that their students participate in real life situations. As a result, the students are more acclimated to, and have developed greater coping skills with community-based learning. There is a great emphasis placed on student to student and student to teacher socialization. In addition, students are coached on appropriate behaviors, and as a result they apply this knowledge in a positive way in the community. It is evident the students are learning critical socialization skills by the proper behavior they exhibit when in public settings.

Individualized instruction in the Park County extended school year program restricts the amount of socialization to which they are exposed. Generally speaking, there are no peers for them to interact with, and since they remain in the classroom, they have no contact with anyone outside of their environment. When students are occasionally placed together very little interaction occurs because there are no peer models for them to observe.

Family Involvement. There is some disagreement between key stakeholders in both school districts as to the extent of family involvement in the extended school year programming. However, all agree that family support is not only relevant to the success of the program, it is essential.

Open communication with families is a strong point in the Coal County program. Staff members feel “small things" are important. Notes are sent home, and if a child does not attend for several days, the staff calls to find out why. Parents also meet with the bus driver to help determine the bus schedule for picking up and dropping off the children. Problems are dealt with immediately at the site and parents feel the staff takes care of problems in a timely manner. 
There is a standing invitation in Coal County for parents to drop by any time during the extended school year. They are welcome to observe and participate if they choose. However, there is little effort to reach out to parents who may not have the time or inclination to participate. Parents are encouraged to meet the group at various activities such as swimming or going to the park. Parents interviewed were very supportive of and satisfied with the program. As one parent remarked, “I really love this program. Everyone has been so nice!” However, it is probably important to note that not all parents participated. It is unknown why as these parents were not available for interviews.

Parents of Park County children were satisfied with their involvement in the IEP process for their children. They felt they had a voice in which skills should be marked as critical. "We work as a team. Everyone kind of agrees.” However, the extent of the involvement of parents during the extended school year program is limited to brief conversations as they drop off or pick up their students. When interviewed, and asked about their involvement, they felt their input was limited to helping in the determination of eligibility.

It is important to note that parents did not always want involvement in the extended school year program. Some of these parents indicated they become frustrated or overwhelmed with too much involvement in the learning process of their children. As one parent stated,

She learns in a totally different way. I found out a long time ago there was no use in me trying to teach her. I tried but it was just so frustrating. I would get so depressed, and I wasn’t doing her any good.

Both programs agree that family involvement and making parents feel welcome is vitally important to the success of any extended school year program. The parents interviewed in each county feel they have a definite voice in determining the type of programming their child receives 
throughout the summer. They believe their suggestions and requests are considered and are honored if at all possible.

Parents in both counties indicated they are comfortable in the amount of involvement they have in the summer programming. Parents point out they realize their children obtain skills in a different way and that it can be very frustrating for them to try to teach the children on their own. They believe that the staff has been trained in dealing with the unique learning styles of their children and should be given room to work.

Community Involvement. The staff in Coal County have been clear in providing an open invitation to community members and others to participate in the activities with the children. For example, during the school year the students with disabilities are paired with buddy partners. Over the course of the summer extended school year, buddy partners stop by just to say hello. This type of arrangement is virtually impossible for Park County because the program set-up is not conducive to group activities.

Community involvement is significantly different at each site. In the Park County program there was little interaction with people outside of the extended school year environment. Service providers remain close to the traditional classroom, and teachers and students alike appear to be uneasy when there are "outsiders" in the room. Some service providers alluded to the idea that the misbehaviors of their students would be seen as direct reflection of their teaching ability. They were therefore reluctant to place themselves and their students in a situation where the eye of the community would be upon them. The people and businesses of the community are not to be faulted for the lack of relationship, as there is not evidence they have ever been given the opportunity to form one. 
Conversely, the Coal County program had a plethora of high quality communications and interactions within the community. Field trips to various points of interest occurred on a daily basis. The children were widely accepted throughout the area and were welcomed with open arms. In many cases they were known by their names in the community. This was evidenced as they traveled to the local grocery store or ice cream shop. As they walked up and down the aisles “shopping”, walked through the open air Farmer’s Market or visited the wildlife refuge, acceptance was obvious. Often, they received the red carpet treatment and in one case, a closed museum was opened especially for them.

School Commitment. There is no doubt both school districts are committed to the mandates of extended school year services and agree students with disabilities would regress without the programming. Both provide certified staff that are experienced and committed to following the goals and objectives listed in each child's IEP. The districts also put forth effort to hire the same special education teachers who work with the children throughout the school year. Schools are instrumental in referrals for services for children and rely on staff for appropriate documentation to support the need for extended school year.

School commitment to extended school year programming hinges largely on the county special education administrator(s). Providing effective services depends on the degree of administrative involvement in the securing of funding sources and their experience in regard to their knowledge of "working the system" to get the best they can for the money.

Both administrators reported their willingness to obtain monies for extended school year programs. However, experience played a large part in their success in finding funding sources. Coal County's special education administrator has been in the system for several years. According 
to service providers, she “does what it takes” to gather funding. They also reported that she is very committed to and believes in the extended school year program.

Park County has a federal programs director overseeing the extended school year program. The summer of the study was her first year in this position, and while she was clearly interested in extended school year, she was somewhat overwhelmed by her new responsibilities. During her interview, she readily admitted that special education was not something about which she knew a great deal, and she depended on others in the county office to guide her. According to the interview, she knew there were grants available to support extended school year but was unsure of how to secure them.

The difference in administrators directly affected the services provided. Because Coal County has an experienced special education director well established in the school district, there has been much opportunity to establish an effective program. The administrator worked closely with the service providers to ensure a continuum of services. She expected and received dedication to extended school year on the part of the staff. Clearly, the success of the Coal County program can in part be attributed to the special education administrator, while Park County’s struggle to be effective also begins at the administrative level.

Since Park County did not have an administrator responsible solely for special education, the extended school year services often got pushed to the "back of the burner." The administrator had a difficult time when there were no teachers who applied for the extended school year program, and she had to resort to calling and begging people to apply. Jobs were posted in compliance with the school district's procedures. “This year, anyone who applied we hired. There were still positions available after the posting process so we resorted to calling teachers and begging them to apply.” Additionally, the administrator felt the children were not encouraged to 
attend and was unsure how to make extended school year more appealing to staff, parents and students.

Virtually all key stakeholders in both school districts believed the most important aspect of extended school year is helping students maintain critical skill levels. They felt it was important to “maintain a balance of what the students are used to without a big change. It's important to continue their routine.” At issue is the concept of key stakeholders about critical skills. Are they related only to academic goals and objectives or are social and life skills also considered critical? Although in both counties key stakeholders voiced commitment to critical social skills, it was clear that how extended school year programs Park County’s extended school year program provided evidence that social and life skills were not considered critical.

As far as whether or not the county is addressing this aspect, the key stakeholders agreed that "for the most part" their county is addressing what has to be done. They also agree there are some changes which could occur to improve the program. Some of these include shorter days over a longer period of time and more activities. Key stakeholders in Park County expressed concern about available socialization for their students with special needs. These stakeholders believed more opportunity needed to be available for students to make choices. "More choices mean more ownership which leads to greater knowledge of how to respond to making choices and thus, fewer inappropriate choices” reflected one key stakeholder.

Cross Case Analysis Summary Coal County’s extended school year program has been designed to be an extension of the student's regular school year. The program emphasizes the critical skills which are difficult to address in a classroom situation. Coal County provides a more in-depth continuum of socialization curriculum, linking the community with the extended school year program, and more specifically with the students. Park County service providers feel that 
many students who should be receiving extended school year services are not. Children with less severe disabilities are not being identified as eligible. They believe the program has been designed for students who are "really low functioning." There is little evidence that active family or community involvement is sought. One service provider expressed concern that, "Parents just want to get rid of them.”

The program in Coal County is successful, in part, due to the significant amount of funding which has been channeled into it. According to Katrina, "It all revolves around financing." Coal County service providers agree their Special Education Director is very supportive and tries very hard to make the program viable. As a result of adequate funding, the program boasts a large staff that is certified and experienced. Additionally, there is money for transportation, field trips, admission costs for various activities and even the occasional trip to the Dairy Queen! The parents in Park County believe the school district has a "set way of doing things", and they do not want to spend the money hiring a teacher for such a small number of students. At least one service provider concurs, “My County doesn’t discourage, but they don’t encourage either.”

As with any program, minor problems exist. Bussing issues appear to be the most problematic in Coal County. Although it happens infrequently, drivers miss picking up some of the children. When the busses arrive late, the entire schedule for the day runs behind. An ongoing problem in Park County is the difficulty in securing an adequate number of service providers. Interviewed teachers indicated they were not interested in working during the summer months.

Overall, in Coal County many extended school year experiences are beneficial. Practical application, using hands on teaching strategies, makes every opportunity a teachable moment. One only has to be there on the last day of the program when the children receive participation ribbons and awards which are geared to honor the progress they have made on their critical skills, to 
realize the true effectiveness of the program. As a whole, the program in Park County elicits mixed responses about its efficacy. There are parents and services providers who feel the services are beneficial to the children. There are other parents and service providers who disagree. One parent, whose child has a 21 page IEP, expressed concern but summed it up by saying, "It is important that they are addressing the critical skills areas. That's what it (extended school year) is designed to do. If they are not addressing those areas, it’s useless.”

\section{Discussion}

This study indicates significant local variance in the interpretation of the definition of extended school year services for students with disabilities in two West Virginia school districts. As the literature review suggests, federal regulations for extended school year implemented by IDEA, 2004, continue to lack substance. Consequently, students are receiving services differently, not only from state to state, but from county to county and school to school. Additionally, the perspectives of administrators, service providers, parents, and community members contribute to the differences in the understanding of what extended school year should look like and are at the root of the problems in implementing extended school year policy equitably.

The data indicate that key stakeholders in both counties hold similar values about extended school year. They believe that extended school year programming is important to students with special needs. However, it appears that key stakeholders hold varying opinions about how extended school year services may best be delivered.

In both cases, as researched, a continuum of services throughout the summer months has proven to be beneficial not only academically and socially but also necessary in order for some students with disabilities to receive a free appropriate education (FAPE). As referenced in the literature review, IDEA provides all students with disabilities a FAPE. In order for students with 
disabilities to receive a FAPE, they sometimes need services not required by other students. Therefore, it is very possible, and in fact very probable that students will disabilities will have need of additional services throughout the year and during the summer months. Extended school year services rely heavily on notions about regression/recoupment but the issue of FAPE cannot be ignored. Extended school year is in place because some students with disabilities are judged as unable to receive a FAPE without it. It is quite probable that many students require extended school year services in order to ensure that they receive a FAPE. However, the costs prevent school districts from making extended school year widely available.

According to IDEA 2004, school districts must provide services regardless of the districts ability to pay. Nevertheless, the study provides ample evidence that the availability of funding relates to the type of extended school year provided. Because of funding issues, many local and state school systems are opposed to extended school year services for children with disabilities (Bonnett, 2002b, p. 5). However, according to the research, when regression is unrecouped over a marked period of time and extended school year services are not in place, FAPE is not being provided. Based on data collection, while both school districts are attempting to ensure their students receive FAPE, there is still much work to do. Key stakeholders at both sites indicated not all students who needed extended school year services were receiving them. Teachers in both counties also think the program is directed primarily toward students with severe disabilities, and that students with less severe disabilities are habitually left out. Extended school year programming should be available for all students with special needs as long as they meet eligibility criteria determined through the IEP process.

The beliefs of school district administrators are powerful in determining how extended school year programs actually operate. By making various resources available, they ultimately 
decide what type of extended school year services will be offered in their counties. It is then the responsibility of the service provider to determine how services will be delivered. The administrators in both Park and Coal County school districts played important roles in the development of their extended school year program.

Coal County’s success can be attributed in part to an administrator who has been actively involved in planning and developing extended school year programming for 15 years. She has helped to mold a seasoned staff who shares her beliefs regarding the needs of children with disabilities. Over the years routines have been established, leading to a fine tuned program. As Park County struggled with extended school year issues, the current administrator was attempting to bring stability to the program. There was a significant lack of collaboration and practically no communication between key stakeholders. According to the literature review, once the practices of extended school year are in place, the focus needs to turn to structures of available services such as coordinating councils, steering committees, and coalitions. These structures have the ability to provide the framework through which schools and communities may plan for successful extended school year programs. It is difficult to determine if a structure in place for either school district would prove beneficial or detrimental. A collaboration or steering committee would involve more people from the community which could lead to a greater variety of creative ideas as to what can be developed for extended school year programs. However, with the involvement of more people in the planning stages, there is a greater chance for conflicts. The federal government, state special education offices, and county special education directors dictate what must be addressed during extended school year, ensuring all mandates are in compliance with federal guidelines. Singularly, the local school system "owns” the program and is responsible for outcomes. "Communities differ in their capacities to respond to the needs of children” (Butera et al., 2000, p. 30). When looking 
at both school districts, it is easy to see the truth in this statement. Although neither school district had any type of structure in place, Coal County’s community involvement provided evidence of informal collaboration.

The most obvious solutions to this situation are not necessarily the easiest. The federal government should overcome it's reluctance to empower local and state governments to establish regulations concerning extended school year and create a means of accountability for their local school systems. Additionally, there is a need for federal guidelines to help key stakeholders remember the intent of extended school year programming.

Funding for extended school year should not be based on the experience of a school district's administrator. Acquired grant monies should not make a notable difference when it comes to the education of any child. According to former U. S. Secretary of Education, Richard W. Riley in a 1999 speech given at the Full Service School-Community Collaboration Conference, “If Uncle Sam can help build jails; he can help build public schools. Let’s get our priorities straight.” Riley reported that, although Congress has provided funding to create school based centers, more must be done. One way is to waive regulations to allow for the mobilization of resources. The federal government should provide adequate funding for mandated programs. It could also fund more projects by making grant opportunities more readily available.

In-service workshops and training should be provided to teachers and community agency workers on social issues which impact students (Cotton, 1997). This is needed because there is no apparent agreement about the importance of extended school year programs. Individual teachers must be educated in all facets of extended school year including eligibility criteria, regression/recoupment, and appropriate delivery of services. Mr. Riley has also stated, 
...the issue is not the latest ranking of schools or students. The issue is not 'good,' 'bad' or 'rank' - but whether we are changing fast enough to save and educate [emphasis added] this generation of young people...whether education has kept up...(Hixson et al., 1996, p. 3).

It is important to note that while funding is critically important for all extended school year programs, there are many resources available at no cost to the school district. These resources lie within the community and include parents, educators, and local people who are willing to help in numerous ways.

\section{You Can't Change The Wind; But You Can Adjust Your Sails}

Having a vision of what children with disabilities could accomplish is as imperative as meeting each child's individual needs. One set program for all students is not conducive to a successful extended school year experience. One key component in the make-up of extended school year lies in the composition of the IEP of each child. Writing an IEP should never become routine or generic in nature since the future of a child with disabilities relies on the proper compilation of the IEP. Based on documentation both school districts address this issue but in completely different ways. Coal County, while still working on the critical skills listed in the IEPs, focuses mainly on the success of the child within his community, and it is evident that the service providers are guided by what they see as important. Park County’s extended school year is geared toward one-on-one programming which emphasizes classroom learning. It was not entirely clear to what extent either extended school year program in the study relied on the IEP of each child to determine curriculum. It does appear that the IEP process is critical in ensuring students individual needs are addressed. 
In order for students with disabilities to be successful, they must acquire critical life skills as well as academic skills. Consistent programming during the summer is one way to maintain these skills. In both counties, teachers outside of the programs and parents of children in the programs indicate they are not sure the needs of the students are being addressed. This comes from a general misunderstanding of the program curriculum. For example, teachers not involved in the extended school year program in Coal County are critical of what they perceive to be “playtime” or "a free babysitting service.” In both school districts the relation between regular school year and extended school year services is often disconnected. In the words of Katrina, Some teachers don’t understand what we do in our extended school year program. When they hear we have been on a trip, they believe we are not addressing academics. This is just not accurate. We always take the teachable moment.

It is easy to criticize what is not understood. Take for instance the "Bob Evans Project” in Park County. To the casual observer, it would appear to be useless, time-consuming busy work. To Ernie and his service provider, it is an opportunity to contribute. As they place crayons, coloring books, and menus in bags for children who will be eating at the local Bob Evans restaurant, what Ernie is really doing is learning a skill which will help him as he encounters reallife situations. 


\section{If Mama Ain’t Happy, Ain’t Nobody Happy}

Another factor in determining how a child’s individual needs are met during extended school year programming is through parents who advocate for their children. One Park County parent expressed this when she said, “I ask for the moon, knowing I’m not going to get it.” Another parent, who is a very strong advocate for her child and a self-proclaimed "troublemaker", when asked if she was making progress for her child, stated, "Well, they're making progress.” She believes the only children who receive extended school year services are the ones whose parents advocate for them. Students who receive extended school year services in both counties are quite likely to have parents who advocate for them. This suggests that students with parents who do not advocate are less likely to receive services.

Parents in both school districts are generally satisfied with the services their children receive and feel it is their responsibility to play a big part in the determination of eligibility for their child. They believe the county honors their requests if it is at all possible. At the IEP meeting, it is a matter of give and take as parents and school staff work together to decide what should be done to best meet the needs of the child. Parents interviewed feel that if they advocate for their children, it is more likely they will receive extended school year services.

\section{The Grass Is Always Greener}

“As good as she’s getting, it could be better.” This philosophy prevails throughout both counties and it is interesting to note that key stakeholders in Coal County believe their program would be more successful if it was geared toward a more individualized delivery of services; whereas in Park County they feel their program would be more meaningful if it had the added feature of center based activities. The Park County program provides face to face contact with 
parents. The service providers maintain daily communication when parents drop off or pick up their children. Conversely, Coal County relies heavily on notes and phone calls. Both counties insist that greater parental involvement would improve the program.

Ideally, a combination all these factors would achieve a more successful extended school year program. In Coal County more individualized activities might assist the program in addressing student's needs. The addition of center based activities in Park County would go far in addressing the socialization issues encountered there. Students would be made more aware of their outside environment and as a result, their actions in real-life situations would reflect this.

In a perfect world, during the summer my daughter would have the same structure that she is used to and in the same time frame. She would receive one-on-one services but also be able to interact with other children.”

\section{You Get What You Pay For}

“It’s a money issue.” “They don’t want to pay for it.” "I think they could have gotten the regular speech teacher if they had paid enough.” The general consensus in both counties is that funding, or the lack of funding, is the bottom line when it comes to determining the outcome of extended school year.

Throughout the observation period, it became increasingly obvious that money in Coal County was much more plentiful than in Park County. This can be attributed, in part, to the expertise of school district's administration attempt to secure funding. Coal County offered their extended school year students many opportunities to participate in activities cost-free. On the contrary, Park County service providers did not have funding with which to offer activities.

School districts providing extended school year services are obligated to investigate funding sources in order to ensure their students receive the best possible programming. Of note is 
the fact that both school districts in the study are rural, have a large number of children in families in poverty, and lack resources. They are embedded in a state and region historically known as economically distressed. No doubt this impacts how extended school year services are provided in a profound way. In the words of one parent, "If you have a lot of money and education, you can open up a lot more doors than if you are poor and uninformed.”

\section{Limitations}

As in all case study research, the intent of this study was to provide a rich description of extended school year and how services are delivered. Under these circumstances certain limitations should be noted. First, data collection for this study comes from only two sites in one state. The two sites are in the southern section of West Virginia and are both rural counties. They are not necessarily representative of statewide extended school year programs. It is therefore difficult to determine how much impact specific demographics have on the implementation of extended school year policies.

It is difficult to determine how much influence a stranger in the room will have on the daily routine. The observer, in any given situation, can take precautions to be as unobtrusive as possible. Unfortunately, there are always students who have difficulty with even the most minor distractions. In the study, no doubt the presence of observers impacted the findings.

The study relies on the self-report of key stakeholders. They were asked their perceptions of extended school year and the answers they gave were based on their knowledge, experiences and the truth as they saw it. As a result, the study is dependent upon the truthfulness of answers given.

The study was conducted for only one summer. There is no student outcome data, pre or post, and as a result there is no method established for recording changes or improvements in the 
children or the program from one year to the next. Clearly positive outcomes for students are the goal of all extended school year services and there is no way of knowing how the findings of the study impacted student achievement. Further investigation is warranted if extended school year programming is to provide competent services to children (Olmi \& Walker, 1995). Future research should include student follow-up throughout the school year to help determine the effectiveness of the extended school year program. This will establish more contextual data to provide a comparison based longitudinal analysis.

\section{Conclusion}

No more pencils? No more books? In West Virginia and across the nation there are thousands of children with special needs exactly like Dennis. These students rely on the expertise of our educational system to identify their special needs and determine the appropriateness of their educational placement. These children depend on the clear interpretation of federal policies embodied in the Individual with Disabilities Education Act (IDEA) to ensure they receive a free and appropriate education (FAPE). Extended school year is one area which must not be overlooked regardless of the availability of funding. In an ideal situation extended school year services would align with the perspectives and beliefs of key stakeholders. In the real world extended school year services are aligned with the available funding. While all agree that funding is important to extended school year programming, there are overriding issues that help determine how these programs should look.

The focus of extended school year must be on child centered programs as described in individual education plans (IEPs). School, family, and community cannot be separate entities where children with disabilities are concerned. Both Coal and Park Counties attempted to implement the four essential components of child centeredness, family involvement, community 
involvement and school commitment. There was evidence that each school district understood the importance of the relationship between the four essential components and an effective extended school year program. It is only when these key components of the child's life come together, in partnership, that the child with disabilities can achieve true success.

According to the National Council on Disability, extended school year programs should work toward the goal of the student becoming a successful, productive citizen (Stinson, n.d.). Through the research process it became obvious that although the extended school year programs of Park and Coal Counties are radically different in structure, the values of both were virtually the same---to help their students maintain much needed skills while becoming successful, productive citizens. Ultimately, the concern is that children learn.

An old African proverb, "It takes a village to raise a child” is especially true for children with disabilities. Communities can provide important guidance and encouragement for all involved. Federal regulations allude to the acceptability of allocating monies for community programs as long as they have been included in the child's IEP. School districts can provide extended school year in creative ways. To be included with children without disabilities, community based programs such as Energy Express or community parks and recreation programs could be a major focus in how extended school year service is provided. Collaboration with either of these programs could also offer opportunities for college students and recent graduates to mentor children with disabilities. These programs serve meals, have on site supervisors, and encourage members of the community to become actively involved. Additionally, these programs can be used in conjunction with extended school year services with the addition of a special education teacher for consultation purposes. 
Extended school year programming must include the notions embodied in current extended school year policies and address critical skills as designated by IEP's. The practices of key stakeholders in both counties reflect their beliefs in the extended school year program and maintaining critical skills. However, as with many school districts across the nation, there is a need for guidance which will help them understand the importance of considering which skills are critical. For example, an IEP team might determine that it is critical for the child to participate in socialization experiences. Another team might determine academic maintenance to be most critical. The behavior of creating an extended school year program that focuses on socialization versus the behavior of creating an academic program might reflect the values of key stakeholders. It is also important to note that addressing critical skill areas for students is insufficient in providing an exemplary extended school year program to students. These programs must consider the importance of family and community connections in designing their activities and take full advantage of the resources available locally. By doing so, students with disabilities may not only avoid losing ground during the summer months, they may also learn important life lessons. If it does indeed take a whole village to raise a child, summer programs including those designated extended school year, may use the opportunity to strengthen the connection between a child's home, school, and community learning. 


\section{References}

Anderson, J. (2000). The need for interagency collaboration for children with emotional and behavioral disabilities and their families. Families in Society, 81(5), 484-493.

Apler, S., \& Noie, D. R. (1987). Extended school year services for students with severe handicaps: a national survey. Journal of the Association for Persons with Severe Handicaps, 12 (1), 61-66.

Bar-Lev, N. B. (1998). Extended school year standards. Retrieved June 21, 2002, from http://www.cesa7.k12.wi.us/sped/issues-esy/esymemo.html

Bar-Lev, N. B. (2004). Update on extended school year (esy) services. Retrieved April 10, 2006, from http://www.cesa7.k12.wi.us/sped/issues-esy/esymemo.html

Bodkins, D. (2002). Letter of clarification. Retrieved April 10, 2006, from http:// wvde.k12.wv.us/ose/FY0303ExtendedSchoolYear.pdf

Bonnett, B. (2002a). Energy Express Case Study. Unpublished manuscript.

Bonnett, B. (2002b). Extended School Year Telephone Survey. Unpublished manuscript.

Browder, D., Lentz, F. E., Knoster, T., \& Wilansky, C. (1988). Determining extended school year eligibility: from esoteric to explicit criteria. The Association for Persons with Severe Handicaps, 13 (4), 235-243. 
Bureau of Instructional Support and Community Services. (2002). Determining an individual student's need for extended school year services. [On-line]. Article from: ERIC File: ECDigest Item \#ED473007.

Butera, G. (1998). Energy Express evaluation 1998. Morgantown, WV: West Virginia University.

Butera, G. (2001). Energy Express evaluation 2001. Morgantown, WV: West Virginia University.

Butera, G., Bonnett, B., McMullen, L., Pae, H., \& Richason, D. (1999). Energy Express evaluation 1999. Morgantown, WV: West Virginia University.

Butera, G., McMullen, L., \& Phillips, R. (2000). Energy Express: Connecting communities and intervention on behalf of school children in West Virginia. Journal of Research in Rural Education, 16 (1), 30-39

Combs, M. (1995, December). Representative Research: a qualitatively driven approach. The Qualitative Report [On-line serial], 2(3). Available: http://www.nova.edu/ssss/QR/QR2-3/combs.html

Cooper, H. (2003). Summer learning loss: the problem and some solutions. Clearinghouse on Early Education and Parenting. Retrieved August 6, 2003, from http://Ericeece.org/pubs/digests/2003/cooper03.html.

Copenhaver, J. (2004). Primer on the provision of extended school year services: for parents and educators. [On-line]. Article from: ERIC File: ECDigest Item 
\#ED483199.

Cotton, K. (1997). School community collaboration to improve the quality of life for urban youth and their families. School Improvement Research Series. Retrieved May 25, 2002, from http:// www.nwrel.org/scpd/sirs/6/topsyn5.html.

Council for Exceptional Children. (n.d.). IDEA '97 Final Regulations. Retrieved January 31, 2006, from http://www.cec.sped.org/law/regulations.

Crowson, R. L., \& Boyd, W. L. (1993). Coordinate services for children: Designing arks for storms and seas unknown. American Journal of Education 101 (2), 140-179.

Extended school year. (September, 2001). [On-line]. Article from: ERIC File: EC Digest Item \#ED458736.

Extended school year program teams with YMCA summer camp for carnival. (August 21, 2004). The Valley News. Retrieved April 10, 2006, from http://www.valleynewsonline.com/news/2004/0821/Oswego_News/073.html

Feagin, J., Orum, A., \& Sjoberg, G. (Eds.). (1991). A case for case study. Chapel Hill, NC: University of North Carolina Press.

Flick, Uwe. (2002). An introduction to qualitative research. London: SAGE Publications. Focus on schools and communities.(1999, Fall). New Designs For Youth Development, 15 (4), Retrieved May 25, 2002, from http://www/cydjournal.org/NewDesigns/ND_99Fall/focus.html 
Garland, C. W., \& Osborne, S. C. (2000). SpecialCare outreach: a project designed to expand child care options for children with disabilities (Office of Special Education Grant No. HO24D60016). Norge, VA: Child Development Resources.

Harvey, V. (1995). Interagency collaboration: Providing a system of care for students. Special Services in the Schools, 10(1), 165-181.

Hazi, H. M. (1998). Policy and legal considerations in supervision. In G. R. Firth and E. F. Pagak (Eds.), Handbook of Research on School Supervision. New York: Macmillan.

Herrington, C. D. (1994). Schools as intergovernmental partners: administrator perceptions of expanded programming for children. Educational Administration Quarterly, 30 (3), 301-323.

Hixson, J., Gholar, C., \& Riggs, E. (1996). Schools trying character education on for size. Journal of Staff Development, 17 (2). Retrieved June 20, 2002, from http://www. nsdc.org

Honig, M. I., Kahne, J., \& McLaughlin, M. W. (1999). School-community collaboration for learning and teaching: findings from research and practice. New Designs for Youth Development, 15 (4), 8-12.

Honig, M. I., Kahne, J., \& McLaughlin, M. W. (2001). School-community connections: Strengthening opportunity to learn and opportunity to teach. In V. Richardson, (Ed.) Handbook of Research on Teaching ( $4^{\text {th }}$ Ed.). Washington, DC: American 
Educational Research Association.

Initiatives: School and Community.(n.d.). Public Education Network. Retrieved May 25, 2002, from http:// www.publiceducation.org/health/projects/plan.htm

Jacobson, K. C., \& Crockett, L. J. (2000). Parental monitoring and adolescent adjustment: an ecological perspective. Journal of Research on Adolescence, 10(1), 65-97.

Kabler, M L., Stevens, T. M., \& Rinaldi, R. T. (1983). Extended school year for the handicapped: legal requirements, educational efficacy, and administrative issues. Journal of Special Education, 17 (1), 105-111.

Karweit, N. (1985). Should we lengthen the school term? Educational Researcher, 14 (6), 19-15.

Katsiyannis, A. (1990). Extended school year policies: an established necessity. Remedial and Special Education, 12 (1), 24-27.

Kraft, R. (1999). Extended school year services: What the courts have said. Retrieved May 25, 2002, from http:// www.nfb.org/fr/fr3/frOOws19

Lockwood, A. T., Stinnette, L. J., \& D’Amico, J. (1996). Collaborating for the common good. New Leaders for Tomorrow’s Schools, 2. Retrieved May 25, 2002, from http://www.ncrel.org/cscd/pubs/lead21/2-1b.html

Margolis, L. (2005). Extended school year services. Future Reflections, 24(1), 3.

Maynard, S., \& Howley, A. (1997). Parent and community involvement in rural schools. [On-line]. Abstract from: ERIC File: EC Digest Item \#E 973.

Mcgill - Franzen, A. (2001, June). Summer reading: importance of giving children access 
to books throughout summer months. Reading Today, 18(6), 10.

McMahon, J. (1994).Extended school year: new directions and implications for school social workers. Social Work in Education, 16(4), 231.

McMillian, J. \& Schumacher, S. (1997). Research In Education: A Conceptual Introduction $\left(4^{\text {th }}\right.$ ed.). New York: Longman.

Miles, M. \& Huberman, A. (1994). An Expanded Source Book: Qualitative Data Analysis ( $2^{\text {nd }}$ ed.). London: Sage.

Missouri Department of Elementary and Secondary Education. (January 25, 2002). Recommendations for extended school year policies. Retrieved May 25, 2002, from http:// www.dese.state.mo.us/divspeced/Compliance/ESY.html

Morse J., Barrett, M., Mayan, M, Olson, K., Spiers, J. (2002, Spring). Verification strategies for establishing reliability and validity in qualitative research. International Journal of Qualitative Methods, 1(2), 5.

New Jersey Department of Education. (February 26, 2002). Extended school year services. Retrieved May 25, 2002, from http://www.state.nj.us/njded/specialed/esy/esy2htm

North Central Regional Educational Laboratory. (1996). School-community collaboration. New Leaders for Tomorrow's Schools, 2. Retrieved May 25, 2002, from http:// www.ncrel.org 
Olmi, D. J., \& Walker, D. W. (1995). Extended school year services:

Prediction, description, and impact of judicial precedence. The Journal of Special Education, 29(1), 72-83.

Oregon Advocacy Center. (February 28, 2002). Special education:

A guide for parents and advocates extended school year programs. Retrieved May 25, 2002, from http:// www.oradvocacy.org/est.htm

Osborne, A. G. (1995). When must a school district provide an extended school year program to students with disabilities? West's Education Law Quarterly, 4(3), 499-507.

Palmaffy, T. (2001). The evolution of the federal role. In C. E. Finn, Jr., A. J. Rotherham, \& C. R. Hokanson, Jr. (Eds.), Rethinking special education for a new century (pp. 1-21). Washington, DC: Thomas B. Fordham Foundation.

Park County Development Authority. (n.d.). Retrieved August 8, 2003, from http://www.parkcounty.org

Patten, P., \& Robertson, A. S. (2002). Focus on after-school time for violence prevention. In Focus Channels, Retrieved June 20, 2002, from http://www.guidancechannel.com

Patton, M. Q. (1990). Qualitative Evaluation and Research Methods.(3 ${ }^{\text {rd }}$ edition) Newberry Park: Sage.

Perras, C. (2002). Family and youth services. Retrieved June 1, 2002, from http://www.cityofseattle.net/humanservices/rys/default.html 
Pinkerton, D. (1990). Extended school year. [On-line]. Abstract from: ERIC File: EC Digest Item: \#E 471

Potter, L. (1999). Extended school year services. The Arc of Maryland, Inc., Retrieved June 20, 2002, from http:// www.thearcmd.org

Prince George County Public Schools. (February 10, 2002). Extended school year. Retrieved June 20, 2002, from http:// www.pgcps.pg.k12.md.us/`spedu/esy.html

Rapport, M. J., \& Thomas, S. B. (1993). Extended school year: Legal issues and implications. Journal of the Association for Persons with Severe Handicaps, 18(1), 16-27.

Riley, R. W. (1999, March). Full service school. Remarks presented at the Community Collaboration Conference, Boston, MA.

Scoggins, J. (n.d.). The Dancing Outlaw. Retrieved February 10, 2004, from www.juliescoggins.com/dancing_outlaw_page.htm

Sharpton, W., Sexton, D., Luster, J. N., \& Long, M. (1998). The measurement of family perspectives on extended school year practices with students in special education. Educational and Psychological Measurement, 58(3), 511-519.

Smrekar, C. (1994). The missing link in school-linked social service programs. Educational Evaluation and Policy Analysis, 16(4), 422-433.

Stagner, M. W., \& Duran, M. A. (1997). Comprehensive community initiatives: Principles, practices and lessons learned. The Future of Children, 7(2), 132-135.

Stake, R. (1995). The art of case research. Thousand Oaks, CA: Sage Publications. 
Stinson, P. (n.d.). Extended school year services for special children. Retrieved July 15, 2005, from http://www.specialchild.com/archives

Tellis, W. (1997a, July). Introduction to case study. The Qualitative Report [On-line serial], 3(2). Available: http://www.nova.edu/ssss/QR/QR3-2/tellis1.html

Tellis, W. (1997b, September). Application of a case study methodology. The Qualitative Report [On-line serial], 3(3). Available: http://www.nova.edu/ssss/QR/QR33/tellis2.html

Understanding Extended School Year. (March 8, 2002). ESY Talk Note, Retrieved April 10, 2006, from http://www.listen-up.org/dnload3/quotes.pdf

Underwood, J. K., \& Mead, J. F. (1995). Legal aspects of special education \& pupil services. Boston: Allyn and Bacon.

Vinluan, M. (2005). Advocacy update: securing access: NTRS and NRPA help students With disabilities excel in academic settings by providing recreational opportunities. Retrieved April 10, 2006, from http://www.findarticles.com/p/articles/mi_m1145/is 11-40/ai_n15947937/print

Wharton, Aldhizer and Weaver. (2003). When are extended school year services necessary? Education Brief, 2.

Wilds, T., \& Liacopoulos, G. (1988). Extended school year services: A consumer perspective on implementation. Journal of the Association for Persons with Severe Handicaps, 13(4), 244-250.

Wischnowski, M. W. (April 12, 1999). Information sheet on extended school year. 
Retrieved May 25, 2002, from http://www.facts.crc.uiuc.edu/esy.html

WVgov. (n.d.) Coal County. Retrieved July 16, 2003, from http://www.wv.gov

WVgov. (n.d.) Park County. Retrieved July 16, 2003, from http://www.wv.gov

Yin, R. (1994). Case study research: Design and methods ( $2^{\text {nd }}$ ed.). Beverly Hills, CA: Sage Publishing. 


\section{Appendix A}

Letter of Request

Special Education Director

March 24, 2003 Park County Schools

Point Pleasant, WV

Dear Ms. Meadows,

Last summer, as part of my comprehensive exams for my doctorate program, I conducted a random telephone survey regarding extended school year programming for children with special needs. As you may recall, you were one of the administrators that I interviewed.

It was my goal to determine the type of services provided and the criteria used for eligibility between counties. I also asked about personal perceptions concerning extended school year programs. Enclosed, please find a summary of that survey.

This summer, I will begin research for my dissertation. I would like to conduct observations of county extended school year programming throughout the length of the program and also interview teachers, service providers, administrators and parents as to their thoughts surrounding extended school year programs.

I have chosen your county as a possible pilot site. Please advise me as to the steps I need to take to obtain permission to conduct my research in your county. Please remember, all my research will be anonymous and participation will be completely voluntary.

I have enclosed protocols of the observation forms and the interview questions that I will be using.

Thank you for your consideration,

Billie E. Bonnett

Doctorate candidate

WVU 


\section{Appendix B}

\section{Anecdotal Classroom Observation Protocol}

\begin{tabular}{|l|r|r|l|}
\hline Date: & Time: & \# of children: & Setting: \\
\hline Description of Physical Environment & \\
\hline Teaching Strategies Observed \\
\hline Classroom Activities/Events \\
\hline
\end{tabular}


Adult/Children Interaction

Children/Children Interaction

Classroom Management Techniques

Special Considerations/Circumstances/Comments 


\section{Appendix C}

Cover Script for Interviews

Good morning (afternoon, evening). Thank you for agreeing to participate in my study. The goal of my research is to determine how counties provide extended school year services for children with special needs. The information gathered will be used for my doctoral dissertation. Your responses will remain anonymous and confidentiality will be maintained. Also, your participation is voluntary and you do not have to respond to every question. For the sake of convenience and accuracy, I would like to tape this interview. Do you have any objections? Again, thank you for agreeing to participate in my study. 


\section{Appendix D}

Administrator Interview Protocol

County:

1. How is extended school year funded in this county?

2. How are extended school year services being delivered this summer (2003)?

3. How are teachers selected to teach ESY?

4. How are IEP goals and objectives addressed during ESY?

5. How is ESY integrated with the regular school program? Is there follow-up? 
6. How do you think your county is doing in delivering extended school year services that meet the needs of children?

7. What, if any, community based programs does your county use for ESY?

8. What barriers exist when working with community programs?

9. What factors facilitate success when working with community programs? 
Appendix E

Service Provider Interview Protocol

County:

1. How were you selected to teach extended school year? What is your certification?

2. How do you deliver extended school year services?

3. How do you communicate with the child's Special Education teacher?

4. Do you receive a copy of the child's goals and objectives from their IEP? How do you address the child's IEP goals and objectives?

5. How are the parents involved with extended school year?

6. How do you report progress to the parents? 
7. What do you feel is important with regards to extended school year? Is the extended year program in this county addressing this aspect? Why or why not?

8. How is extended school year integrated with regular school? Is there follow-up?

9. How do you think this county is doing in delivering extended school year services that meet the needs of children? 


\section{Appendix F}

Teacher Interview Protocol

County:

1. What do you feel is important with regards to extended school year? Is the extended school year program in this county addressing this aspect? Why or why not?

2. What criteria is used to determine extended school year eligibility?

3. How do you decide which children are eligible for extended school year?

4. Who participates in the decision making for eligibility?

5. How do you collect data to help determine extended school year eligibility? 
6. How are the IEP goals and objectives addressed during extended school year?

7. How is extended school year integrated with regular school? Is there follow-up?

8. How do you think this county is doing in delivering extended school year services that meet the needs of children? 


\author{
Appendix G \\ Parent Interview Protocol
}

County:

1. What role do you play as a member of your child's IEP committee?

2. How did your child qualify for ESY?

3. How are ESY services designed to meet your child's individual needs?

4. How is your child's progress during extended school year reported to you?

5. Who do you contact if you have a question concerning your child's IEP or ESY? 
6. What do you feel is important with regards to extended school year? Is the extended school year program in this county addressing this aspect? Why or why not?

7. How do you feel about the services your child receives through ESY? 
Appendix H

Extended School Year 2003

Critical Skills Checklist

\begin{tabular}{|c|c|c|c|c|c|c|c|c|c|c|c|c|c|c|c|}
\hline $\begin{array}{c}\text { Critical } \\
\text { Skill }\end{array}$ & 7/1 & 7/2 & $7 / 3$ & $7 / 8$ & 7/9 & $7 / 10$ & 7/15 & 7/16 & $7 / 17$ & $7 / 22$ & $7 / 23$ & $7 / 24$ & $7 / 29$ & 7/30 & 7/31 \\
\hline & & & & & & & & & & & & & & & \\
\hline & & & & & & & & & & & & & & & \\
\hline & & & & & & & & & & & & & & & \\
\hline & & & & & & & & & & & & & & & \\
\hline & & & & & & & & & & & & & & & \\
\hline & & & & & & & & & & & & & & & \\
\hline
\end{tabular}


Appendix I

Extended School Year Documentation

STUDENT

BIRTHDATE

CURRENT SCHOOL YEAR

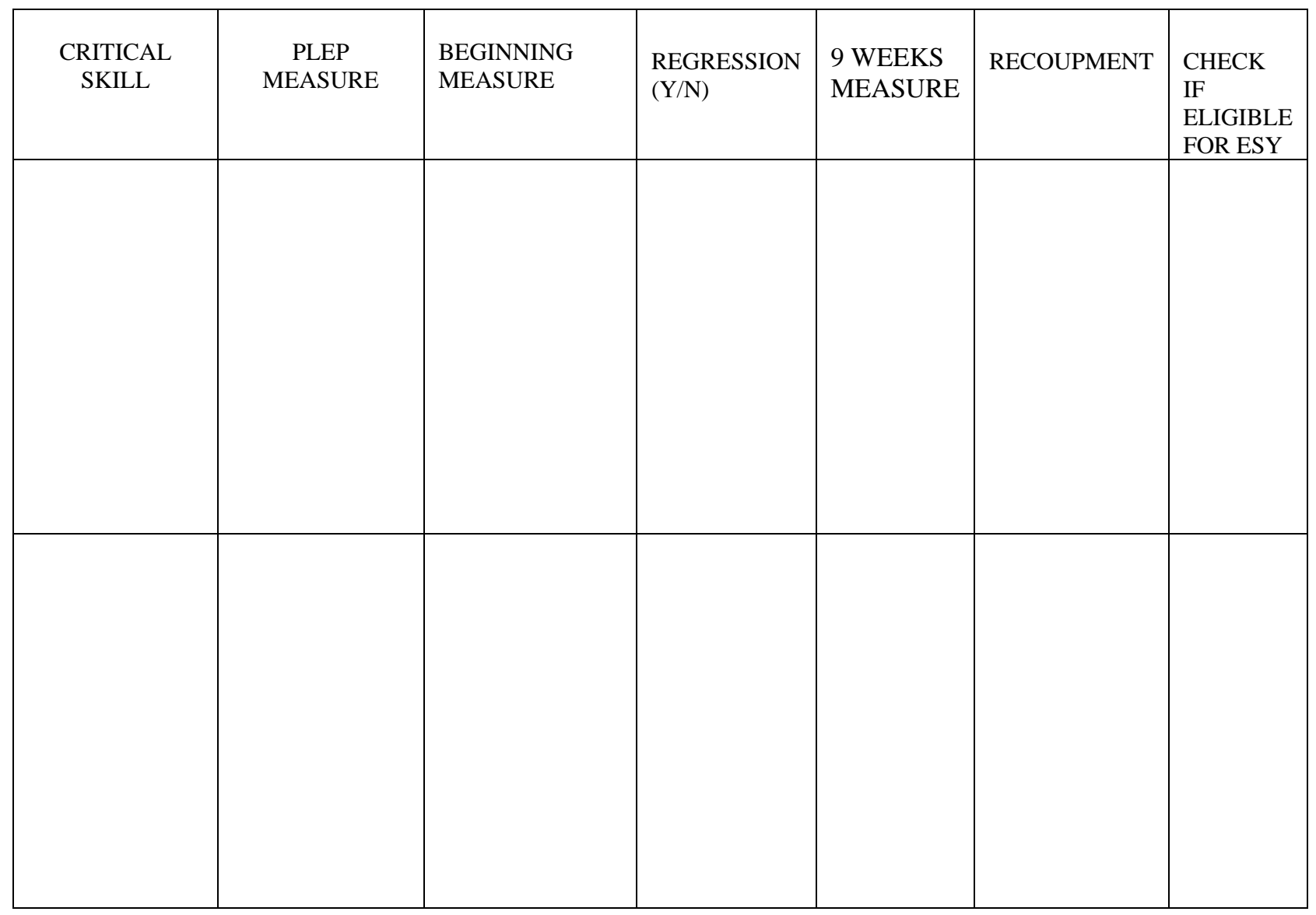

